INSTITUTE OF BIOCHEMISTRY, BIOLOGICAL RESEARCH CENTER OF THE HUNGARIAN ACADEMY OF SCIENCES

\title{
Genome-wide transcriptome analysis of dendritic cells in a model of acute and persistent infection
}

PhD Dissertation

Filkor Kata

2013. 
"It is our choices what we truly are, far more than our abilities" (J.K. Rowling, Harry Potter and the Chamber of Secrets) 


\section{Publications directly related to the subject of the dissertation}

Kata Filkor, Zoltán Hegedűs, András Szász, Vilmos Tubak, Lajos Kemény, Éva Kondorosi, István Nagy Genome wide transcriptome analysis of dendritic cells identifies genes with altered expression in psoriasis PLOS One (in press)

István Nagy*, Kata Filkor*, Tibor Németh, Zsuszanna Hamari, Csaba Vágvölgyi, Attila Gácser In vitro interactions of Candida parapsilosis wild-type and lipase deficient mutants with human monocyte-derived dendritic cells BMC Microbiol. 2011 May 29;11:122. doi: 10.1186/1471-2180-11-122. IF 3,044

* authors contributed equally to this work 


\section{Table of contents}

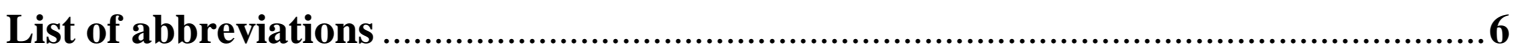

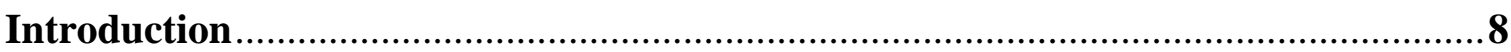

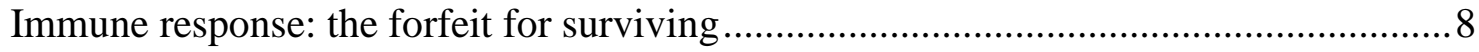

The control of Staphylococcus aureus (S. aureus) infection ....................................... 9

Tolerance to LPS is essential for the control of inflammation.....................................11

Dendritic cells: gatekeepers between innate and adaptive immune response ................11

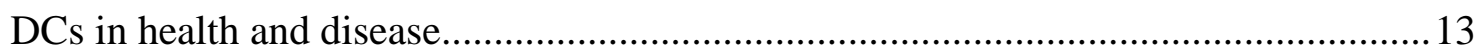

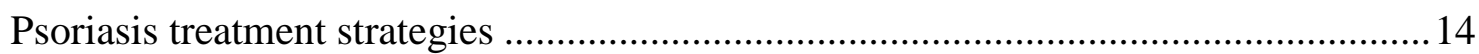

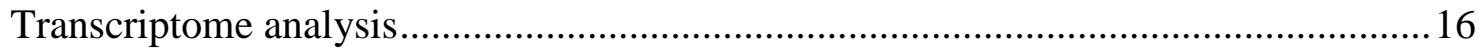

Aims

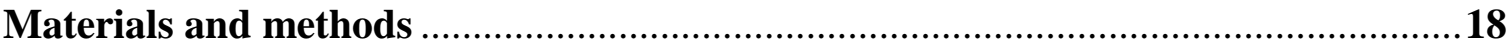

In vitro generation of primary human dendritic cells................................................... 18

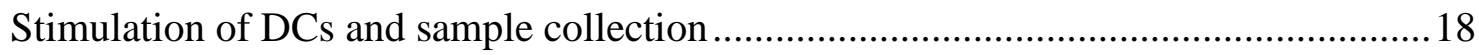

Quantitative reverse transcriptase polymerase chain reaction (QRT-PCR) ..................19

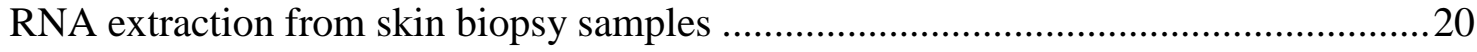

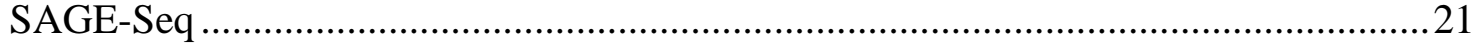

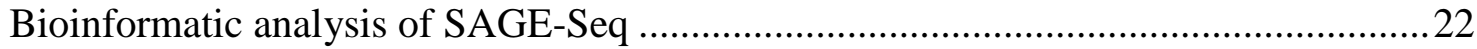

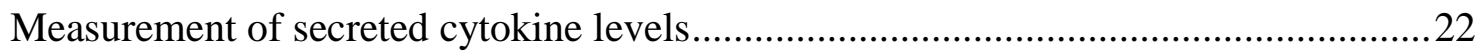

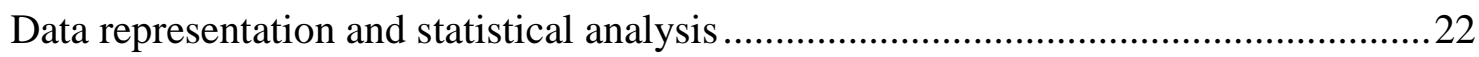

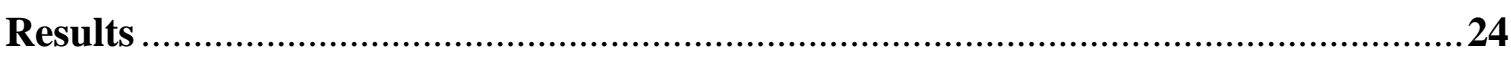

SAGE-Seq studies demonstrate that PGN stimulation and re-stimulation has appreciable impact on the gene expression profile of primary human iDCs

PGN stimulation has significant impact on the relative gene expression of inflammation-related effector molecules and their respective receptors

PGN stimulation has distinct effect on the relative gene expression of TNF- $\alpha$ and the

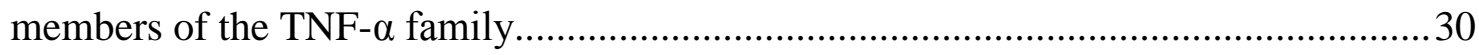

SOCS proteins have function in the regulation of PGN induced inflammation .............32

Tryptophan deprivation has possible role in the control of Staphylococcal infection ...34

PGN stimulation induces cell cycle arrest and resistance to apoptotic process .............35

The relative gene expression of the members of TNF- $\alpha$ super family from psoriatic samples show strong correlations with our in vitro model 
TNF- $\alpha$ blockade down regulates pro inflammatory cytokines at relative gene expression and secreted protein level in $\mathrm{T}+\mathrm{PGN}$ samples

\section{Discussion}

PGN stimulation and re-stimulatin has appreciable impact on the gene expression profile of primary human iDCs

The relative gene expression profile of pro-inflammatory mediators after single or prolonged PGN stimulation show strong correlations with autoimmune diseases

Tryptophan deprivation has central role in the control of Staphylococcal infection and the induction of autoimmune inflammatory diseases

PGN stimulation has distinct effect on the relative gene expression of the negative regulators of inflammatory processes

The down regulation of the anti-inflammatory members in TNF- $\alpha$ superfamily has essential role in the pathogenesis of psoriasis

The blockade of soluble TNF- $\alpha$ significantly reduces the relative gene expression and secreted protein level of pro-inflammatory cytokines.

Summary 


\section{List of abbreviations}

ABI-SOLiD Applied Biosystems Sequencing by Oligonucleotide Ligation and Detection

\begin{tabular}{|c|c|}
\hline ANOVA & analysis of variance \\
\hline APC & antigen presenting cell \\
\hline bp & base pair \\
\hline CCL & chemokine (C-C motif) ligand \\
\hline CCR & chemokine (C-C motif) receptor \\
\hline CD & cluster of differentiation \\
\hline cDNA & complementer DNA \\
\hline CXCL & chemokine (C-X-C motif) ligand \\
\hline Cyc & cyclin \\
\hline DAMP & danger-associated molecular pattern \\
\hline DGE & digital gene expression tag profiling \\
\hline ELISA & enzyme-linked immunosorbent assay \\
\hline FADD & Fas-associated death domain \\
\hline FBS & foetal bovine serum \\
\hline GM-CSF & granulocyte-macrophage colony stimulating factor \\
\hline gp130 & glycoprotein 130 \\
\hline iDC & immature dendritic cell \\
\hline IDO & indolamine 2,3-dioxigenase \\
\hline IFN- $\alpha$ & interferon- $\alpha$ \\
\hline IL & interleukin \\
\hline KEGG & Kyoto Encyclopedia of Genes and Genomes \\
\hline Kynu & kynureninase \\
\hline LPS & lipopolisaccharide \\
\hline mDC & mature dendritic cell \\
\hline MHC & mayor histocompatibility complex \\
\hline $\operatorname{miR}$ & microRNA \\
\hline mRNA & messenger RNA \\
\hline
\end{tabular}




\begin{tabular}{ll} 
NF-KB & nuclear factor $\kappa \mathrm{B}$ \\
NGS & next generation sequencing \\
p & probability value \\
PAMP & pathogen-associated molecular patter \\
PGN & peptidoglycan \\
PRR & pattern recognition receptor \\
QRT-PCR & quantitative reverse transcriptase polymerase chain reaction \\
S. aureus & Staphylococcus aureus \\
SAGE-Seq & serial analysis of gene expression followed by sequencing \\
SEM & standard error of the mean \\
SNP & single nucleotide polymorphism \\
SOCS & suppressor of cytokine signaling \\
TGF- $\boldsymbol{\text { Th }}$ & transforming growth factor $\beta$ \\
Th & T helper \\
TLR & Toll-like receptor \\
TNFAIP & tumor necrosis factor alpha induced protein \\
TNFSF & tumor necrosis factor superfamily \\
TNF- $\alpha$ & tumor necrosis factor $\alpha$ \\
\hline
\end{tabular}




\section{Introduction}

\section{Immune response: the forfeit for surviving}

Plants and animals are constitutively exposed to various microbes present in the environment including commensal and pathogenic microorganisms. Despite the perpetual presence of pathogens, infections still develop infrequently, because all multicellular organisms have evolved defense mechanisms to combat against harmful microbes [1].

The highly organized mammalian immune system can be divided into innate and adaptive (acquired) immunity. The innate immune system denotes an evolutionary more conservative, however less specialized defense mechanism. The non-specific effector cells (i.e. epithelial cells, such as keratinocytes) can eliminate invading pathogens and attract specific effector cells (i.e. macrophages, dendritic cells (DCs)) to the site of the infection by the secretion of pro-inflammatory mediators, such as cytokines and chemokines. The cellular elements of the innate immunity recognize and respond to pathogens in a generic way although it does not confer long-lasting protective immunity to the host. On the other hand, the adaptive immune response exhibits a more sophisticated and complex mechanism than the innate immunity with the ability to recognize and remember specific pathogens/antigens which finally results in a more pronounced immune response after the re-infection with the respective pathogen/antigen. Hence, for the development of immunological memory antigen presentation is essential. For this, professional antigen presenting cells (APCs, such as dendritic cells) take up invading pathogens at the periphery and after migrating to lymphoid organs they present antigens primarily to $\mathrm{T}$ lymphocytes. Antigen presentation to naïve $\mathrm{T}$ lymphocytes is called as lymphocyte activation. This activation process leads to the clonal expansion of the effector $\mathrm{T}$ lymphocytes which makes cells capable for fighting against pathogenic microbes in a microbe specific way. Taken together, the successful activation of both the innate and the adaptive immune system finally results in the elimination of the invading pathogens, which is essential for the host's survival (Figure 1). 


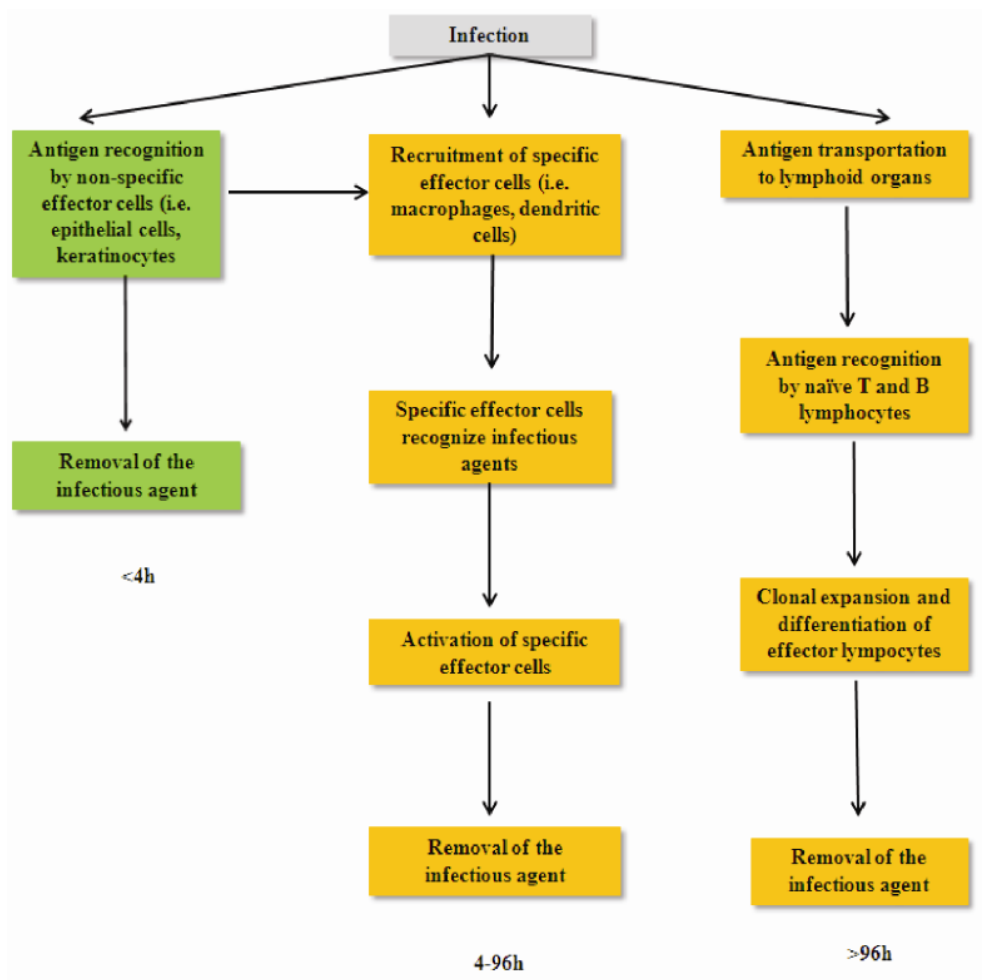

Figure 1. Time course and different processes involved upon the activation of innate (green panels) and adaptive (orange panels) immune response.

Beside secreting cytokines and chemokines, epithelial cells are also forming tight junctions which serve as an effective mechanical barrier between the host and the environment. This is particularly important as the members of the commensal microflora are present on epithelial surfaces, such as the gut and skin. On the epithelial surfaces, the commensal microflora occupies niches which are suitable for bacterial growth and they create special environment, where pathogens are not able to grow [2]. Epithelial cells are also capable for producing cationic antimicrobial peptides, for example psoriasin, cathelicidin (LL-37), ribonuclease 7 and numerous defensins [3] [4], which all have direct antimicrobial activity, thereby controlling commensal microflora.

\section{The control of Staphylococcus aureus (S. aureus) infection}

In order to induce the appropriate immune response, the host must detect the invading pathogens first, primarily through the pattern recognition receptors (PRRs). The best characterized PRRs are the Toll-like receptors (TLRs) which recognize a wide variety of pathogen-associated molecular patterns (PAMPs, such as peptidoglycan; PGN) expressed by microorganisms including viruses, bacteria, fungi and protozoa [5] [6]. In addition to PAMPs, endogenous host-derived danger signals (danger-associated 
molecular patterns; DAMPs) like heat-shock proteins, hyaluronan and other degradation products from necrotic tissues can activate the TLRs [7], [8].

Although Staphylococcus aureus (S. aureus) is the member of the normal microflora of the skin and the nasal passage, moreover $20 \%$ of the human population are long-term carriers of the bacteria [9], S. aureus is responsible for the majority of skin infections [10].

As the Staphylococcal cell wall is mostly composed by PGN [11], PGN is the most potent PAMP of $S$. aureus, inducing the host's immune response by cross-linking the TLR2. Figure 2 shows a simplified scheme of signaling pathway induced by ligand stimulation of the representative TLRs. Briefly, the activation of TLR2 with PGN induces the MyD88-dependent signaling cascade which finally results in the activation of NF-kB. Together with the activation of ERK, JNK and p38, this leads to the enhanced production of effector molecules, such as IL-12p40, IL-1 and TNF- $\alpha$. In this process, TIRAP controls MyD88 activation and also regulates the phenotypic maturation of dendritic cells by increasing the expression of CD40, CD80 and CD86 on the cell surface [12].

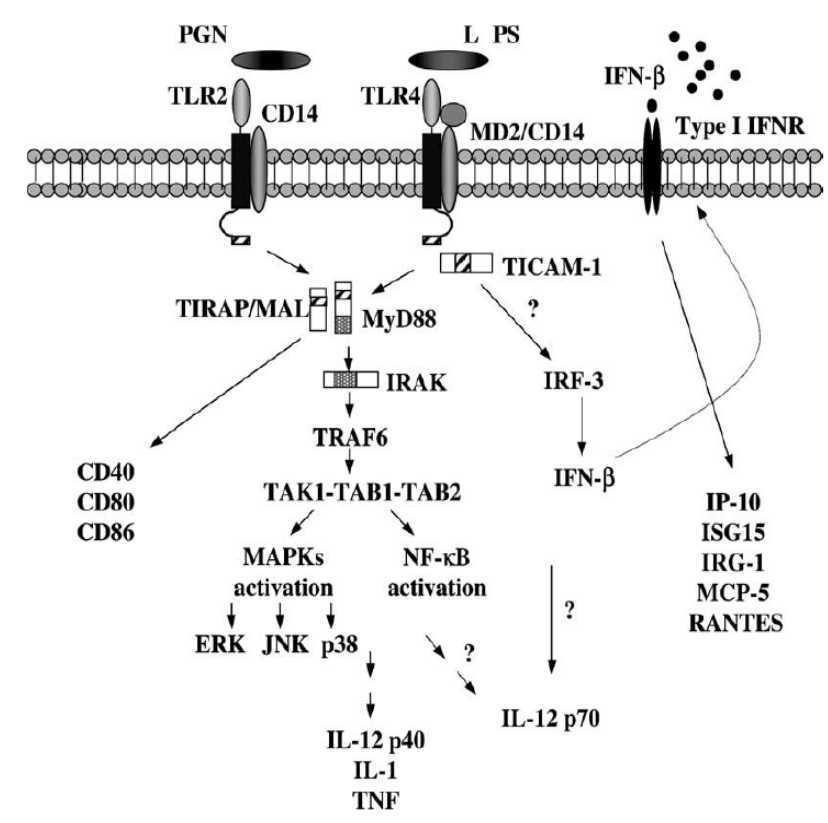

Figure 2. The cross-linking of TLRs with its respective ligand is essential for pro-inflammatory mediator production and dendritic cell maturation [12]. 


\section{Tolerance to LPS is essential for the control of inflammation}

As the inflammation causes dramatic changes in tissue physiology, inflammatory responses must be strictly regulated because uncontrolled inflammation could lead to serious pathologic conditions such as septic shock, autoimmunity, atherosclerosis, etc [13]. On the other hand, there are a wide variety of regulatory mechanisms built in the TLR4-mediated signaling pathway, such as the production of anti-inflammatory cytokines, and the induction of the negative regulators of the TLRs, i.e. SOCS1[14],[15] TNFAIP3 [16] preventing the host from the harmful side effects of the uncontrolled inflammation.

These molecules have pivotal role in the long-lasting hyporesponsiveness of the cells and organisms to prolonged/repeated LPS stimulation, which phenomenon is called as LPS tolerance [17], [18]. For a long time LPS tolerance was thought to be a consequence of receptor desensitization[19], [20]. Recently, Foster et al. demonstrated that the transient silencing of pro-inflammatory genes at chromatin level also has essential role in the maintenance of LPS tolerance [21]. They treated primary mouse macrophages with LPS once or repeatedly and they examined the relative gene expression of inflammatoryrelated genes. In brief, they found that cytokines such as IL-6 or IL-1 $\beta$ were up regulated after the first LPS stimulation, however they were not re-induced or induced to a much lesser degree after the second LPS challenge (defined as tolerizeable). In contrary to cytokines, the relative gene expression of antimicrobial peptides (i.e. cathelicidin-related antimicrobial peptide) seemed to be inducible after the second LPS treatment (defined as non-tolerizeable) in order to protect the host from the impending pathogens and the tissue damage caused by uncontrolled inflammation. The more accurate analysis demonstrated that covalent histone modifications have important role in the maintenance of LPS tolerance. After investigating the promoters of tolerizeable and non-tolerizeable genes, Foster et al. found that although the promoters of both classes were inducibly acetylated (this is characteristic for transcriptional activity) in naïve macrophages, only the nontolerizeable promoters were re-acetylated after LPS treatment in tolerant cells.

\section{Dendritic cells: gatekeepers between innate and adaptive immune response}

As mentioned earlier, professional APCs are essential for the induction of the adaptive immune response. Figure 3 demonstrates that dendritic cells serve as a bridge between innate and adaptive immunity. In the periphery, DCs function as immune 
sentinels, because they are able to sense threatening pathogens by their PRRs [22] which is followed by phagocytosis and clathrin mediated endocytosis in order to take up invading pathogens [23]. Soon after pathogen uptake, DCs migrate to lymphoid organs, for example lymph nodes, spleen, etc. In lymphoid organs, DCs complete their maturation processes and attract $\mathrm{T}$ lymphocytes by the elevated production of cytokines and chemokines. By the up regulation of major histocompatibility complex (MHC) II DCs are able to present processed pathogenic antigens to $\mathrm{T}$ lymphocytes through $\mathrm{T}$ cell receptors (TCRs) [24] which finally leads to the activation of the adaptive immune response.

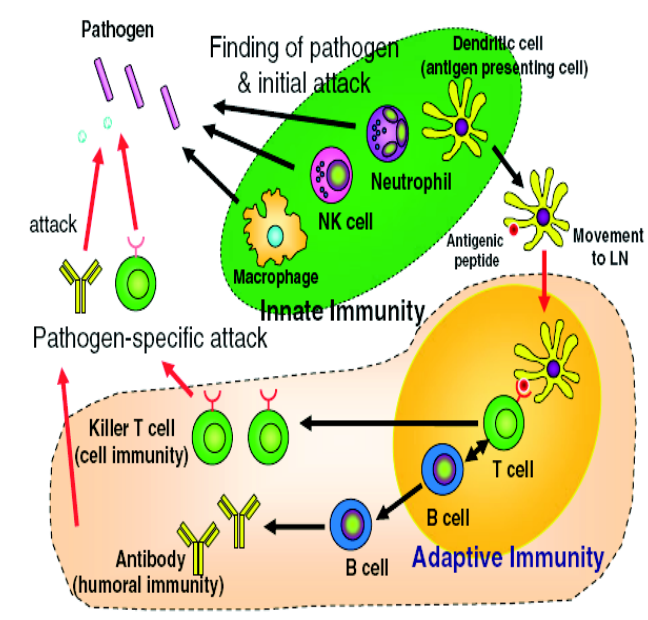

Figure 3. Dendritic cells serve as a bridge between innate and adaptive immunity [25]

The majority of DCs function as immune sentinels at the periphery i.e. in the skin where they called Langerhans cells. Because DCs only constitute the minority of the peripherial blood form where their separation is almost impossible, the investigation of human DCs is based on DC differentiation strategies from DC precursors which finally results in a usable ex vivo model system [26].

For this, $\mathrm{CD}_{1} 4^{+}$monocytes are most frequently used as precursors for DC differentiation. In the presence of recombinant granulocyte-macrophage colony stimulating factor (GM-CSF) and interleukin-4 (IL-4) IL-4-DCs are generated [27]. Other research groups reported that $\mathrm{CD} 14^{+}$monocytes stimulated with recombinant GM-CSF and interferon- $\alpha($ IFN- $\alpha)$ differentiated into IFN-DCs. Further analysis of both cells confirmed immature DC phenotype (iDC) which is characterized by a moderate expression level of costimulatory molecules like CD83 and CD25 [28], [29] and conserved phagocytic capacity. 
It is also possible to generate mature dendritic cells (mDCs) from iDCs by treating them with TNF- $\alpha$, IL-1, or challenging them with microbial agents. mDCs are characterized with elevated pro-inflammatory cytokine production, increased antimicrobial response and enhanced antigen presenting capacity [30].

\section{$\underline{\text { DCs in health and disease }}$}

It is important to note that the role of DCs is not limited to the initiation of the adaptive immune response. In some pathologic conditions, the function of DCs is disturbed, and they induce immune response against self molecules. This process is called autoimmunity, which often results in serious, multi-organ autoimmune diseases, such as systemic lupus erythematosus (SLE) [31], or psoriasis [32].

Psoriasis is one of the most common multifactorial autoimmune-like disease worldwide, as it affects approximately $2 \%$ of the population. This chronic disease mainly affects the skin, however severe joint destructions (psoriatic arthritis) and nail alterations could be detected beside skin discrepancies [33].

As a multifactorial disease environmental factors like microbial infections, trauma or stress initiate psoriasis development in genetically susceptible individuals. Environmental stimulation leads to the release of self DNA and RNA from stressed keratinocytes which form complexes with LL-37 antimicrobial peptide. This complex activates DCs through their TLR7 and TLR9 receptors [34], [35] and leads to the production and the release of pro-inflammatory mediators such as IFN- $\alpha$. The enhanced local level of IFN- $\alpha$ together with GM-CSF stimulates monocytes to differentiate into DCs [36]. IFN- $\alpha$ primed DCs than transform naïve $\mathrm{T}$ lymphocytes into Th1 and Th17 cells which migrate to the skin where they have central role in the initiation of psoriatic plaque formation, partly by elevated pro-inflammatory cytokine secretion [37].

The malfunction of the skin's immune system in psoriasis induces massive mononuclear leukocyte (T lymphocyte, neutrophils, plasmacytoid DCs and CD11 ${ }^{+}$DCs) infiltration compared with normal, non-lesional skin biopsy samples (Figure 4). CD11 ${ }^{+}$ DCs from psoriatic lesions express high level of TNF- $\alpha$ and inducible nitric oxide synthase (iNOS) both playing central role in pathogen elimination. In addition to TNF- $\alpha$ production, $\mathrm{CD} 11 \mathrm{c}^{+} \mathrm{DCs}$ secrete $\mathrm{T}$ cell and keratinocyte activating cytokines, such as IL- 
23 and IL-20, respectively. The elevated amount of maturation markers suggest that these DC types are able to present antigens to T lymphocytes.
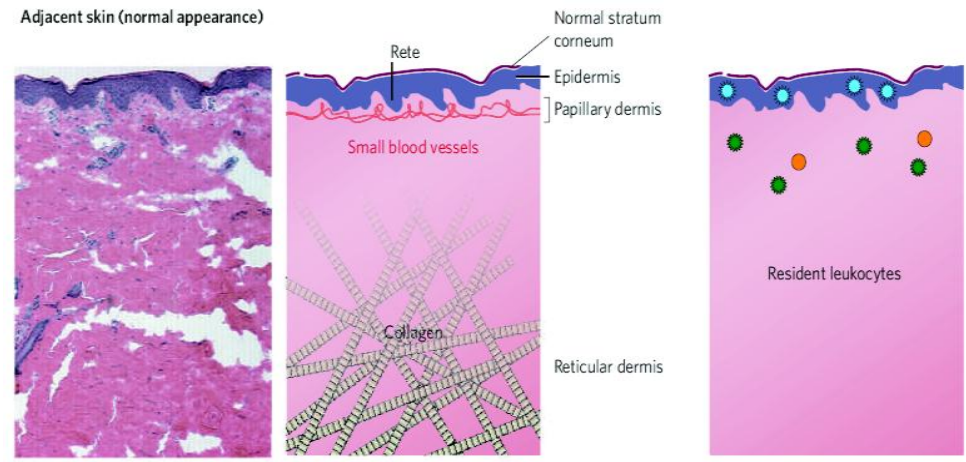

i) Langerhanscell

- Immature CD11c $D C$

Inflammatory DC

Mature DC
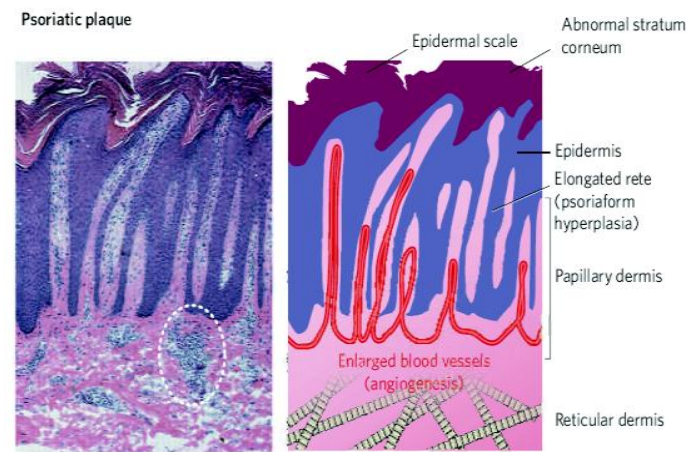

- Mature DC

O Plasmacytoid DC

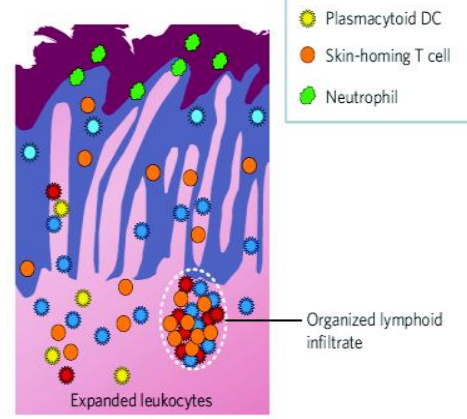

Figure 4. Massive immune cell infiltrations and epidermal hyperproliferation characterize psoriasis [38].

The enhanced pro inflammatory cytokine and chemokine production by professional immune cells finally leads to massive keratinocyte hyperproliferation in psoriatic lesional skin biopsy samples. Furthermore, psoriatic keratinocytes are resistant to apoptotic signals, and their survival mechanisms are up regulated, thus histologic analysis represent robust epidermal expansion (acanthosis). Moreover, the absence of the granular layer leads to incompletely differentiated keratinocytes (parakeratosis) which is another hallmark of psoriasis [38].

\section{Psoriasis treatment strategies}

Investigations of psoriasis at a molecular level demonstrated the up regulation of a wide variety of pro-inflammatory mediators. Thus, both conventional and biologic therapeutics approaches target the immune system. Conventionally immunosuppressive therapies include classical systemic (methotrexate, cyclosporins, retinoids) or topical treatment (anthralin, corticosteroids, salicylic acid, vitamin D analogues) and/or phototherapy (climatoterapy, broadband UVB, narrowband UVB and psoralen with 
ultraviolet A radiation (PUVA)) are applied (Figure 5). As these conventional treatment strategies are based on the global suppression of the immune system, often serious, sometimes life-threatening side effects are detected [39], [40], [41], [42].

On the other hand, the inhibition of the respective pro-inflammatory mediators with antibodies or soluble receptors became the mainstream of biologic therapy. The right panel of Figure 5 contains those biologic agents which are accepted or are at the approval stage. TNF- $\alpha$ is the main cytokine involved in the pathogenesis of psoriasis, most part of the biologic therapy agents target this cytokine, although the prevalent usage of the TNF$\alpha$ blocking agents can cause gastrointestinal symptoms or liver damage [43]. Yet, TNF- $\alpha$ blockers are became the world's top selling medicines in 2012.

Based on the fact that Th17 cells have pivotal role in the pathogenesis of psoriasis, IL-17 blocking antibodies are also under extensive study. Ixekizumab [44] and secukinumab [45] are antibodies against IL-17, however brodalumab [46] is a soluble IL17 receptor, but all of them are successfully used to treat moderate to severe plaque type psoriasis. In order to treat psoriasis, some other cytokines such as IL-23 and IL-22 can also be hampered by blocking antibodies in order to repress the elevated cytokine production of Th17 cells.

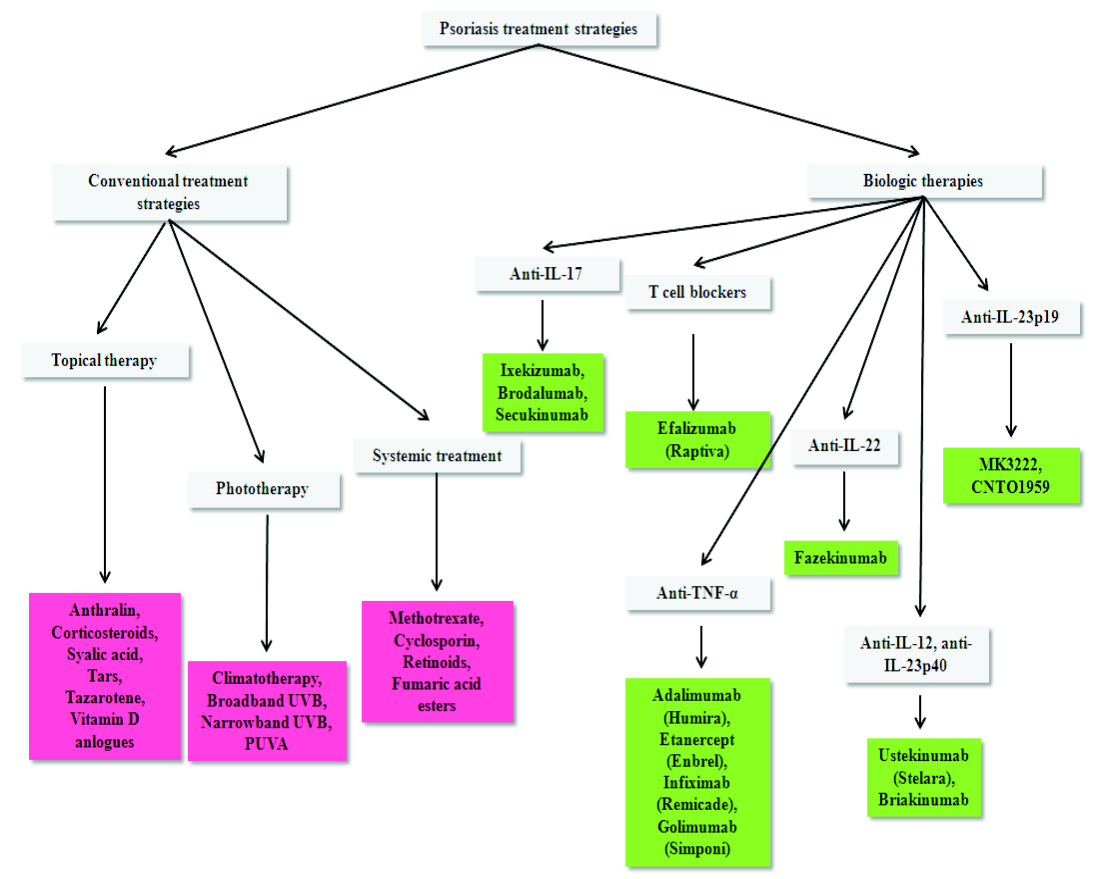

Figure 5. Conventional treatment strategies and biologic therapies are used in psoriasis [43], [33], [47]. 


\section{Transcriptome analysis}

In microarray experiments cDNA is hybridized on an array of complementary oligonucleotide probes corresponding to the gene of interest, and the relative abundance of mRNA is estimated from its hybridization capacity to the relevant probe [48]. However one drawbacks of this approach is the limited number of probe sets included on the chip.

Recently launched technology, called next generation sequencing (NGS) has rapidly substituted microarray due to, among others, it has improved accuracy and throughput and decreased cost-per-experiment ratio. Beside de novo sequencing of genomes, NGS technology is also very powerful when it comes to genome resequencing, SNP, MNP and indel identification [49]. Furthermore, NGS offers an unprecedented opportunity to jointly analyze cellular transcriptional activity without any information of the nature of the transcript.

One of these applications is the whole transcriptome sequencing (RNA-Seq). During this application, ribosomal RNA is removed from total RNA and the RNA leftover is fragmented by RNAseIII restriction enzyme. The RNA fragments are size selected and the 50-200 nucleotide long fractions are used for library preparation followed by sequencing. This gives a unique opportunity to detect all the expressed exons of the respective genes, but also to detect new splice variants and to identify novel, unannotated exons.

In order to analyze alterations at mRNA level, another approach, called serial analysis of gene expression followed by sequencing (SAGE-Seq; also known as digital gene expression tag profiling; DGE) can be used. This method is based on the capture of polyadenylated mRNAs by oligo(dT) containing magnetic beads only the captured mRNA is sequently analyzed. Compared with the traditional serial analysis of digital gene expression (SAGE) [50] SAGE-Seq gives remarkably higher data correlations between libraries. 
Aims

The aims of our investigations were

- To get a global view on the relative gene expression changes of primary human immature dendritic cells (iDCs) upon challenging them once or repeatedly with $S$. aureus derived PGN, a widely used TLR2 ligand.

- To carry out pathway analysis based on the results of SAGE-Seq experiments in order to investigate the impact of PGN challenge on gene sets and signaling pathways.

- To compare the relative gene expression pattern of the selected genes between immature and mature dendritic cells (mDCs).

- To examine the gene expression pattern of selected genes on skin biopsy samples.

- To investigate the impact of soluble TNF- $\alpha$ antibody on the relative gene expression of selected genes. 


\section{Materials and methods}

\section{$\underline{\text { In vitro generation of primary human dendritic cells }}$}

Human peripherial blood mononuclear cells were isolated from buffy coats of healthy individuals (Hungarian Red Cross) by Ficoll Paque Plus (GE Healthcare) density gradient centrifugation as previously described [51]. In brief, PBMCs were allowed to adhere for 2 hours on each wells of a 6 -well plate (Sarstedt). Adherent monocytes were washed extensively with pre-warmed phosphate-buffered saline (PBS, Gibco) in order to remove non-adherent cells (macrophages, lymphocytes, etc.). iDCs were obtained from monocytes by cultivating them in RPMI-1640 medium (Gibco) which was supplemented with $10 \%$ heat-inactivated foetal bovine serum (FBS, Gibco) and 1\% penicillin/ streptomycin solution (Gibco) in the presence of 1000 unit/ml recombinant human granulocyte-macrophage colony stimulating factor (GM-CSF, Sigma) and $1000 \mathrm{unit} / \mathrm{ml}$ recombinant human interferon $-\alpha$ (IFN- $\alpha$, Sigma) for 5 days. mDCs were obtained from iDCs by $10 \mathrm{ng} / \mathrm{ml}$ recombinant human tumor necrosis factor- $\alpha$ (TNF- $\alpha$, R\&D Systems) stimulation for 24 hours. Cells were maintained at $37^{\circ} \mathrm{C}$ in an atmosphere of $5 \%(\mathrm{v} / \mathrm{v})$ $\mathrm{CO}_{2}$ in air.

\section{$\underline{\text { Stimulation of DCs and sample collection }}$}

Both iDCs and mDCs were treated with Staphylococcus aureus (S. aureus) derived peptidoglycan (PGN, Sigma) according to the model described on Figure 6. Briefly, iDCs and mDCs were left untreated (hereafter defined as naive, $\mathrm{N}$ ) or stimulated with $10 \mu \mathrm{g} / \mathrm{ml}$ PGN once (hereafter defined as N+PGN) or twice (hereafter defined as T+PGN), in order to mimic acute or persistent infection, respectively.

In some experiments, soluble chimeric monoclonal anti-TNF- $\alpha$ antibody (infliximab, Remicade, Schering-Plough) was added to primary monocytes in parallel with GM-CSF and IFN- $\alpha$. Infliximab has a long half life of approximately 10 days, which ensured the neutralization of all secreted TNF- $\alpha$ during iDC generation. Moreover, freshly prepared infliximab was added to the culture supernatants along with PGN stimulations in order to neutralize de novo secreted TNF- $\alpha$.

Total RNA and cell culture supernatants were collected at 27 and 48 hours, that is 3 and 24 hours post-second PGN treatment. 


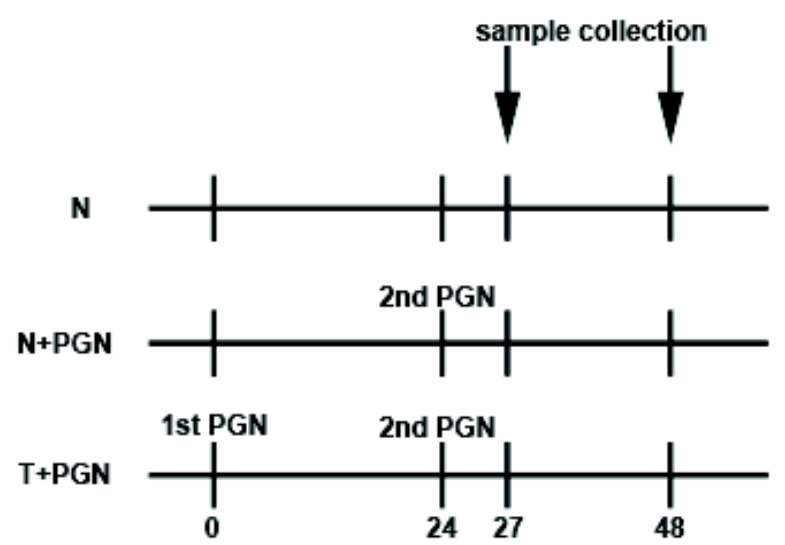

Figure 6. The model of acute $(\mathrm{N}+\mathrm{PGN})$ and persistent $(\mathrm{T}+\mathrm{PGN})$ infection.

\section{Quantitative reverse transcriptase polymerase chain reaction (QRT-PCR)}

Total RNA was extracted from iDCs and mDCs using RNeasy Plus Mini Kits (Qiagen) according to the manufacturer's instructions. The quality and the quantity of extracted RNA were determined using NanoDrop (Thermo Scientific), Qubit (Life Technologies) and Bioanalyzer (Agilent) measurements.

cDNA was synthesized from 100ng of total RNA by using High Capacity RNA to cDNA Kit (Life Technologies) according to the manufacturer's instructions. The relative abundance of selected mRNAs is determined by QRT-PCR by using StepOne Plus RealTime PCR system (Life Technologies). Reactions were performed by using TaqMan Gene Expression Master Mix (Life Technologies) for commercially available TaqMan probes (Life Technologies) or Power SybrGreen Master Mix (Life Technologies) for SybrGreen based QRT-PCR assays. The primer sets used in QRT-PCR experiments are listed in Table 1. As controls we used reaction mixtures without cDNA. All of the measurements were performed in duplicate with at least three biological replicates. The ratio of each mRNA is relative to $18 \mathrm{~S}$ rRNA calculated by using the $\Delta \Delta \mathrm{Ct}$ method. 
A

\begin{tabular}{cc} 
A & Assay number \\
\hline 18S rRNA & Hs99999901 \\
CXCL8 & Hs001714103_m1 \\
CXCL9 & Hs00171065 \\
IL-6 & Hs00174131 \\
IL-10 & Hs99999035_m1 \\
SOCS3 & Hs010000485 \\
TNF- $\alpha$ & Hs00174128_m1 \\
TNFAIP6 & Hs01113602_m1 \\
TNFAIP8 & Hs00226190
\end{tabular}

B

\begin{tabular}{|c|c|c|c|}
\hline Gene & Forward primer $\left(5^{\prime} \rightarrow 3^{\prime}\right)$ & Reverse primer $\left(5^{\prime} \rightarrow 3^{\prime}\right)$ & $\begin{array}{l}\text { Product length } \\
\text { (nucleotide) }\end{array}$ \\
\hline $\mathrm{CXCL} 7$ & AACTTGGCGAAAGGCAAAGAGG & AGCATCTGGGTCCAGGCAGATT & 201 \\
\hline CXCLI0 & TTGTCCACGTGTTGAGATCATTG & GCAGCCTCTGTGTGGTCCATC & 188 \\
\hline CCLl & CTTCACCAGGCTCATCAAAGCTG & TCTGGAGGGTACCTGCATG & 150 \\
\hline CCR8 & CAAAGGCTGTCACTAAGGTCCCGC & CCAGGATGACCAGGCTGTTTCCCA & 206 \\
\hline gp130 & TCCCTGCCTGTGACTTTCAAGGG & AGGTCCTTTGGAAGGTGGAGCTTG & 140 \\
\hline IL-10RA & GTCAGTCCCAGCCCAAGGGTAG & AGCTCTGTCCCATGAGCGTCTG & 154 \\
\hline IL-17RA & GCATCACCACAGGCGGTGG & AGGGATGGGCTTGGGCAGGT & 100 \\
\hline SOCS1 & CGCACATTCCGTTCGCACG & AAGTGCACGCGGATGCTCG & 224 \\
\hline SOCS2 & CAGGGAATGGCAGAGACACT & TGGCAGAGAGAGAAGGGATG & 163 \\
\hline TNFAIP3 & GCTGAAAACGAACGGTGACGG & AGAGACTCCAGTTGCCAGCGG & 159 \\
\hline Cyclin B2 & TGGCTCCAAAGGGTCCTTCTCCC & CTGCAGAGCTGAGGGTTCTCCCA & 139 \\
\hline Cyclin D1 & TCAAGTGTGACCCGGACTGCCT & ACGTCGGTGGGTGTGCAAGC & 161 \\
\hline FADD & CTGGGGAAGAAGACCTGTGTGCAG & GCTCTGTCAGGTTGCGGGGG & 144 \\
\hline TGF- $\beta$ & TGTCACCGGAGTTGTGCGG & GGCCGGTAGTGAACCCGTTGATG & 131 \\
\hline Kynureninase & GCTGAGGCACTTCAGGGAGTG & TGACCATAGGCTGCTATTTTGG & 192 \\
\hline $\begin{array}{l}\text { Indolamine2,3- } \\
\text { dioxigenase }\end{array}$ & AGACTGCTGGTGGAGGACATG & GGCGTCATAAGCTTCCCGCAGG & 161 \\
\hline
\end{tabular}

Table 1. Specific exon spanning gene expression assays based on commercially available predesigned TaqMan (A) or SybrGreen (B) methods used in QRT-PCR experiments

\section{$\underline{\text { RNA extraction from skin biopsy samples }}$}

Shave biopsies from uninvolved and involved skin of psoriatic patients and control skin biopsies from the breast and stomach area were collected as described previously [52]. After the removal of the subcutaneous tissue, skin biopsies were incubated overnight at $4^{\circ} \mathrm{C}$ in Dispase solution (Roche Diagnostics). On the following day, the epidermis was separated from the dermis and samples were mounted in $1 \mathrm{ml}$ of TRIzol Reagent (Life Technologies) to which $400 \mu$ l chloroform (Sigma) was added and vortexed vigorously. Samples were centrifuged at $13000 \mathrm{rpm}$ for 10 minutes and the upper phase was loaded onto gDNA eliminator spin columns of the RNeasy Plus Mini Kits (Qiagen). Subsequent 
RNA extraction and quantification as well as cDNA synthesis and QRT-PCR were performed as described above.

All tissue samples were taken with the patient's informed consent and the approval of the local ethics committee. The study was conducted according to the declaration of Helsinki Principles.

\section{$\underline{\text { SAGE-Seq }}$}

SAGE-Seq was performed using SOLiD SAGE Kit (Life Technologies) according to the manufacturer's instructions. The summary of the method is described on Figure 7. Briefly, purified total RNA was bind to Dynabeads Oligo (dT) EcoP15 magnetic beads in order to capture polyadenylated RNAs. cDNA was synthesized on the magnetic beads by using SuperScript III Reverse Transcriptase and E. coli DNA polymerase. Next, NlaIII restriction was performed in order to generate GTAC containing sticky end at the complementer DNA strand. Barcode adaptor A (P2 Seq-IA-EcoP15I) was ligated which contains an EcoP15 restriction enzyme recognition site and truncated internal adaptor sequence. An EcoP15I digestion was carried out in order to cleave the construct off from the magnetic beads. EcoP15I restriction also resulted in a 2 base-pair long overhanging tag. Adaptor B was ligated to 5' end of each tag which contains the P1 primer binding site. Each library was amplified in an emulsion PCR, sequencing beads deposited onto sequencing slide and sequenced on SOLiD V4 System (Life Technologies).

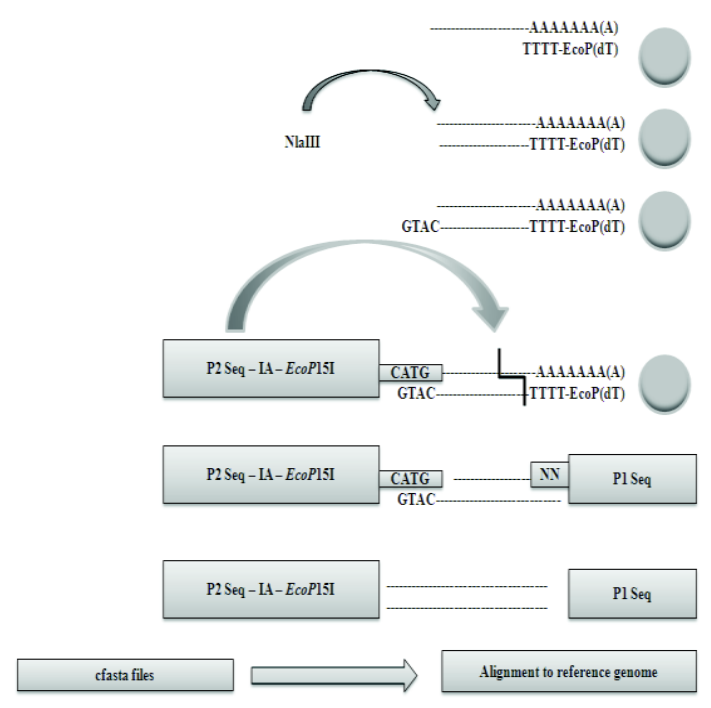

Figure 7. SOLiD SAGE-Seq workflow 


\section{Bioinformatic analysis of SAGE-Seq}

For mapping SAGE-Seq tags on the human transcriptome we created virtual libraries containing all the possible 18 bases length sequences of ENSEMBL human transcript data set (version GRCh37.58) located next to an NlaIII restriction site. Virtual tag libraries and the preprocessed and quality filtered SAGE-Seq libraries were uploaded into an in-house developed data warehouse. Mappings were done by the relational database engine of the data warehouse in a way that only perfect matches over the entire $22 \mathrm{bp}$ length of the 18bp tag plus 46bp NlaIII restriction site were allowed. During the mapping process, the system tracked the so-called multiple mapping events where tags detected in the experiments could be assigned to more than one transcript. Statistical comparison of SAGE-Seq data from different samples was performed using the Bayesian method [53]. In brief, the method performs a key-by-key comparison of two key-count distributions by generating a probability that the frequency of any key in the distribution differs by more than a given fold factor from the other distribution. The algorithm performs the statistical analysis by taking into account that the potential difference in the total size of the tag libraries compared. In our analysis we used a 2-fold factor difference of transcript expression level as the subject of the Bayesian statistical evaluation. The algorithm returns a probability value $(\mathrm{P})$ for each tag describing the chance that the detected count numbers represent a fold difference of the tag concentration between the investigated samples greater than or equal to 2 . The change of the tag expression was accepted as significant if $\mathrm{P}$ was above 0,95 .

\section{Measurement of secreted cytokine levels}

Harvested cell culture supernatants were centrifuged and the concentrations of secreted TNF- $\alpha$ and CCL1 were measured by Quantikine Human Immunoassay Kits (R\&D Systems) following the manufacturer's instructions. Serial dilutions of the respective recombinant human proteins were used to generate standard curves. The optical density of each wells were determined by using microplate reader (FLUOstar Optima, BMG Labtech) set to $450 \mathrm{~nm}$ with a wavelength correction set to $540 \mathrm{~nm}$.

\section{Data representation and statistical analysis}

Data show average \pm standard error of the mean. The significance of differences between sets of data was determined by Student's paired t-test or one-way ANOVA 
following Neuman-Keuls post-hoc test using Graph Pad Prism for Windows. A probability value (p) of less than 0,05 was considered significant. 


\section{Results}

\section{$\underline{\text { SAGE-Seq studies demonstrate that PGN stimulation and re-stimulation has }}$}

\section{appreciable impact on the gene expression profile of primary human iDCs}

In order to get a global view on the gene expression pattern of primary human iDCs after single or prolonged PGN stimulation, SAGE-Seq experiments were performed. Bioinformatics analysis of SAGE-Seq data evidenced that single or prolonged PGN stimulation resulted in significant alterations of the relative gene expression of altogether 5411 genes $(\mathrm{p}<0,05)$. Between naïve $(\mathrm{N})$ and once stimulated $(\mathrm{N}+\mathrm{PGN})$ samples 2840 genes were found which had significant changes in their expression pattern (Figure 8). Importantly, 805 out of 2840 were uniquely characteristic for this category. 3647 genes changed their relative gene expression pattern between naïve and twice stimulated $(\mathrm{T}+\mathrm{PGN})$ samples. 1016 out of 3647 were uniquely characteristic between naïve and $\mathrm{T}+\mathrm{PGN}$ samples. The relative gene expression of 566 genes uniquely changed between $\mathrm{N}+\mathrm{PGN}$ and T+PGN samples. Finally, in this current study we mainly focused on those genes, because they represent the differences between acute and persistent Staphylococcal infections at a relative gene expression level.

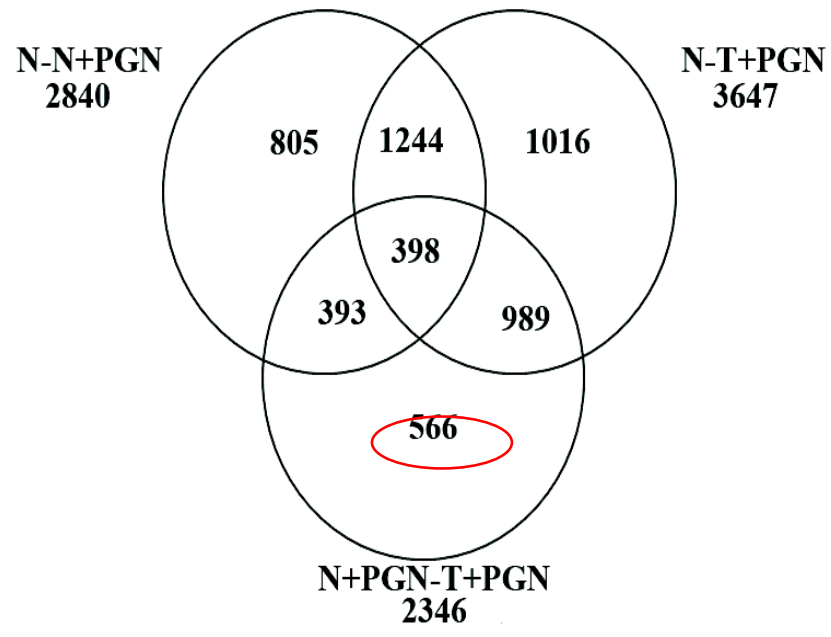

Figure 8. The distribution of those 5411 genes which were differently expressed between naïve $(\mathrm{N})$, single (N+PGN) or prolonged PGN (T+PGN) stimulated iDCs

To characterize the potential relevance of the alterations resulted by single or prolonged PGN stimulation, pathway analysis was carried out by BioProc (Table 2A) and Kegg (Kyoto Encyclopedia of Genes and Genomes, Table 2B) pathway analysis softwares. Although Kegg allows for a more accurate analysis by providing consistent 
and standardized annotations by linking individual genes to components of the KEGG biochemical pathways [54] we used both pathway analysis tools to reduce the possibility of false results.

After single or prolonged PGN stimulation compared with naïve cells both BioProc and Kegg analysis resulted in massive enrichment of pathways from the function group "Immune response" "Apoptosis" and "Motion". Importantly, comparison between $\mathrm{N}+\mathrm{PGN}$ and $\mathrm{T}+\mathrm{PGN}$ samples resulted in more down regulated pathways than up regulated from these function groups, which strongly suggest the induction of tolerogenic mechanisms after prolonged PGN stimulation. In contrary with "Immune response" "Apoptosis" and "Motion", the pathway analysis of the function group "Cell cycle" and "Energy production" demonstrates that single or prolonged PGN stimulation significantly down regulates the expression of the members of these function groups. It is important to note here that BioProc pathway analysis also demonstrated the induction of several (8) pathways from "Cell cycle". Single or prolonged PGN stimulation also results in the induction of a number of other pathways compared with naïve cells, for example "Systemic lupus erythematosus" or "Autoimmune thyreoid diseases".

A

\begin{tabular}{c|c|c|c|c|c|c} 
A & \multicolumn{2}{|c|}{ N-N+PGN } & \multicolumn{2}{c|}{$\mathbf{N}$ - T+PGN } & \multicolumn{2}{c}{ N+PGN - T+PGN } \\
\hline & Up regulated & $\begin{array}{c}\text { Down } \\
\text { regulated }\end{array}$ & Up regulated & $\begin{array}{c}\text { Down } \\
\text { regulated }\end{array}$ & Up regulated & $\begin{array}{c}\text { Down } \\
\text { regulated }\end{array}$ \\
\hline Immune & 100 & 0 & 94 & 0 & 4 & 14 \\
response & 18 & 2 & 18 & 1 & 0 & 8 \\
Apoptosis & 8 & 38 & 4 & 27 & 0 & 0 \\
Cell cycle & 8 & 0 & 3 & 0 & 0 & 6 \\
Motion & 15 & 15 & 0 & 12 & 0 & 0 \\
Energy & 0 & 23 & 26 & 23 & 0 & 14 \\
production & 03 & & & &
\end{tabular}

B

\begin{tabular}{c|c|c|c|c|c|c} 
& \multicolumn{2}{|c|}{ N-N+PGN } & \multicolumn{2}{c|}{ N - T+PGN } & \multicolumn{2}{c}{ N+PGN - T+PGN } \\
\hline & Up regulated & $\begin{array}{c}\text { Down } \\
\text { regulated }\end{array}$ & Up regulated & $\begin{array}{c}\text { Down } \\
\text { regulated }\end{array}$ & Up regulated & $\begin{array}{c}\text { Down } \\
\text { regulated }\end{array}$ \\
\hline Immune & 19 & 0 & 16 & 1 & 1 & 12 \\
response & 1 & 0 & 1 & 0 & 0 & 0 \\
Apoptosis & 0 & 4 & 0 & 3 & 0 & 0 \\
Cell cycle & 0 & 2 & 0 & 3 & 0 & 0 \\
Energy & 0 & 7 & 2 & 6 & 0 & 3 \\
production & 3 & 7 & & & 0
\end{tabular}

Table 2. The number of significantly up and down regulated pathways after single or prolonged PGN stimulation in iDCs which was performed by BioProc (A) and Kegg (B) pathway analysis 
Based on the results of the pathway analysis and considering that NlaIII has recognition site of approximately every 200-300 nucleotides in the human genome we investigated the expression patterns of individual tags (tag represents the short subsequence of a gene which is used to identify gene transcripts in SAGE-Seq experiments; a gene may contain more than one tag) (Figure 9). We found that 132 tags out of 427 tested were re-inducible, as in $\mathrm{N}+\mathrm{PGN}$ samples significant gene expression down regulation was detected compared with naïve cells, in contrast, we detected gene expression up regulation in $\mathrm{T}+\mathrm{PGN}$ samples compared with $\mathrm{N}+\mathrm{PGN}$ (Figure 9A). The comparison of these results with the pathway analysis demonstrated that "Antigen presentation" and pathways from autoimmune diseases such as "Systemic lupus erythematosus" and "Autoimmune thyreoid disease" fell into this category (data not shown). Based on the results of Foster et. al [21] we were mostly interested in tolerizeable tags (Figure 9B). Tolerizeability means that single PGN stimulation results in a robust induction in the relative gene expression compared with naïve cells however in $\mathrm{T}+\mathrm{PGN}$ samples significant relative gene expression down regulation was detected compared with N+PGN samples. The importance of the decreased relative gene expression level after prolonged PGN stimulation plays role in is the prevention of the host against the development of serious side effects resulting from uncontrolled inflammation. In this study 181 tags out of 427 fell into this pattern category; most of them from the "Toll-like receptor signaling pathway". In contrast, the expression of 40 tags out of 427 monitored were down regulated in N+PGN samples compared with naïve cells and a more robust down regulation was detected after prolonged PGN stimulation (Figure 9C): the members of "Cell cycle" and "Apoptosis" function group fell into this category. Finally, 74 tags out of 427 tested were robustly up regulated in N+PGN samples as compared to naïve cells and a more significant relative gene expression up regulation was detected after prolonged PGN stimulation (Figure 9D). Comparing these results with the pathway analysis the members of the "Cytokine and chemokine signaling pathway" (the member of the function group "Immune response") fell into this category. 

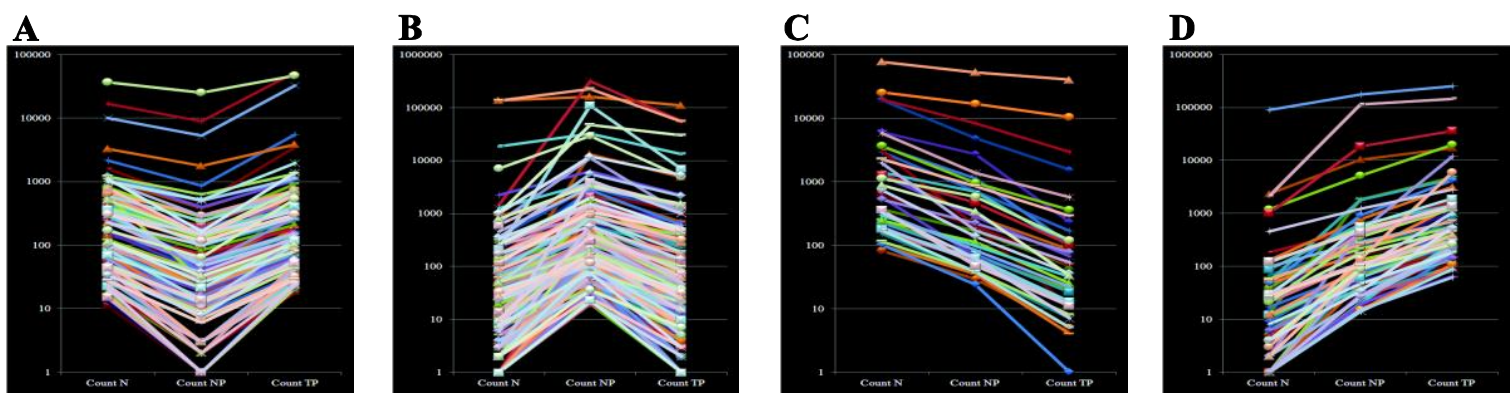

Figure 9. The number of tags from each different gene expression pattern groups

Taken these findings together, our data suggest that our experimental model together with SAGE-Seq is a valuable approach to monitor the impact of acute and persistent infection. Formerly, microarray experiments were used to globally investigate the impact of a given stimulation at a gene expression level, although the results were hardly repeatable by other validation procedures. The reason for this is the fact that in microarray experiments cDNA is hybridized on an array of complementary oligonucleotide probes corresponding to the gene of interest, and the relative abundance of mRNA is estimated from its hybridization capacity to the relevant probe [48]; the probes, may, however cross-hybridize. Nevertheless, we also aimed to validate the SAGE-Seq results on a set of genes. Based on the results of the pathway analysis and enrichment studies we have chose members of the "Immune response", "Apoptosis" and "Cell cycle" function group which were more accurately analyzed at relative gene expression and secreted protein level by QRT-PCR and ELISA. The validation procedure was carried out on mature dendritic cells (mDCs) as well, because the presence of foreign antigens and the inflammatory milieu induces DC maturation process. During maturation, the antigen processing capacity of DCs decreases while their antigen presentation and expression of co-stimulatory molecules increases [55]. We hypothesized that these features may result in significant difference in their relative gene expression pattern as compared to iDCs after single or prolonged PGN stimulation according to the model described at Figure 6.

\section{PGN stimulation has significant impact on the relative gene expression of}

\section{inflammation-related effector molecules and their respective receptors}

Pathway analysis of SAGE-Seq data demonstrated that PGN stimulation resulted in robust gene expression up regulation of cytokines and cytokine receptors. The expression of the majority of the cytokines were more robustly up regulated in T+PGN samples 
compared with N+PGN samples (Figure 9D), however in case of some cytokines prolonged PGN stimulation resulted in expression down regulation as compared to N+PGN samples. Thus, we first examined the relative gene expression alterations of inflammation-related effector molecules and their receptors after single or prolonged PGN stimulation by QRT-PCR.

In iDCs, single PGN stimulation resulted in gene expression up regulation of the majority of investigated effector molecules such as CXCL8 (Figure 10B), CCL1 (Figure 10E), IL-6 (Figure 10F), and IL-17A (Figure 10H) compared with naïve cells. Furthermore, in case of all four genes a more robust gene expression up regulation was detected in $\mathrm{T}+\mathrm{PGN}$ samples as compared to N+PGN samples. Surprisingly, although IL10 (Figure 10G) has an anti-inflammatory role, single or prolonged PGN stimulation caused identical alterations in the relative gene expression pattern with the previously mentioned pro-inflammatory effector molecules. In mDCs we detected the same relative gene expression patterns as for iDCs, however the values of the relative gene expression in case of CXCL8 (Figure 10B) and CCL1 (Figure 10E) were less prominent then in iDCs.

Interestingly, the relative gene expression of the neutrophil-attractant chemokine, CXCL7 (Figure 10A) was significantly down regulated in N+PGN samples in both iDCs and mDCs compared with naïve cells. Uniquely from the function group "Cytokines and cytokine receptors" prolonged PGN treatment had no effect on the relative gene expression of CXCL7 in neither iDCs nor mDCs compared with naïve cells.

In contrary to the previously mentioned effector molecules, the IFN- $\gamma$ inducible CXCL9 (Figure 10C) and CXCL10 (Figure 10D) genes showed different expression pattern after single or prolonged PGN stimulation. We demonstrated that CXCL9 (Figure 10C) in mDCs and CXCL10 (Figure 10D) in both iDCs and mDCs are tolerizeable, as single PGN stimulation resulted in gene expression up regulation, however prolonged PGN stimulation caused robust gene expression down regulation compared with both naïve cells and N+PGN samples. Furthermore, in iDCs the relative gene expression of CXCL9 (Figure 10C) was significantly down regulated after both single or prolonged PGN stimulation compared with naïve cells.

Because the cytokines show altered gene expression, we aimed to determine the impact of PGN stimulation on the relative gene expression pattern of their respective 
receptors. Our data demonstrate that single or prolonged PGN stimulation significantly down regulated the relative gene expression of IL-10RA (the receptor of IL-10, Figure 10K) and IL-17RA (the receptor of IL-17A, Figure 10L) in both iDCs and mDCs. In addition, the same gene expression alterations were detected in the case of gp130 (IL-6 signal transducer, the receptor of IL-6, Figure 10J) in iDCs, although in mDCs we demonstrated the tolerizeability of gp130. Moreover, we detected the tolerizeable capacity of CCR8 (the receptor of CCL1, Figure 10I) in both iDCs and mDCs.

Based on these results which are similar with SAGE-Seq data we concluded that after single or prolonged PGN stimulation the host cell maintain critical balance between inflammation and tolerance in order to eliminate impending pathogens and to protect the host against the harmful side effects resulting from uncontrolled inflammation. Furthermore, our data demonstrate the decreased pro-inflammatory cytokine producing capacity of mDCs compared with iDCs which phenomenon is strongly supported by the fact that mDCs have central role in antigen presentation, in contrast iDCs are mostly involved in antigen uptake and the recruitment of other effector cells to the site of the infection. Moreover, the investigation of the relative gene expression of the respective receptors of inflammation related effector molecules suggests the absence of autocrine regulatory mechanisms, as most of the receptors were down regulated.

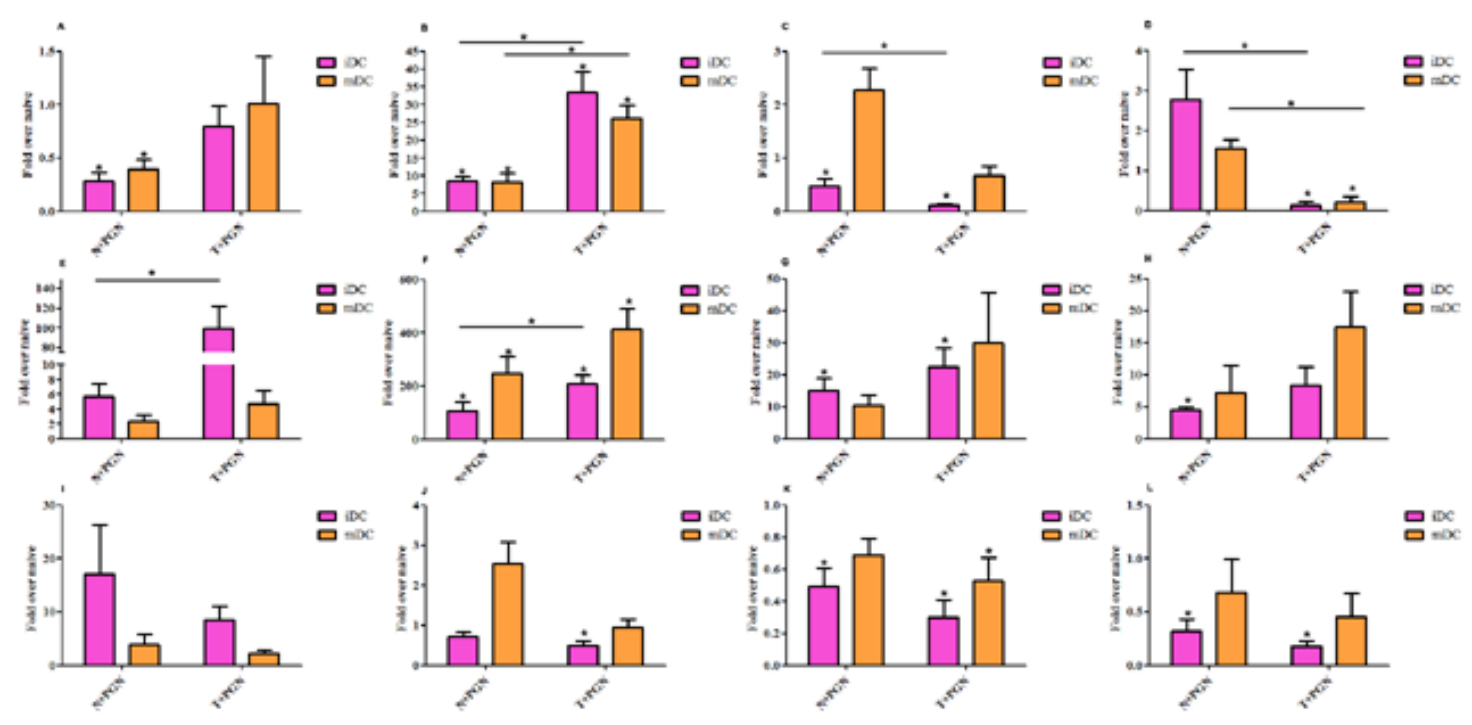

Figure 10. PGN stimulation significantly modulates the relative gene expression of cytokines, chemokines and cytokine receptors in DCs (A: CXCL7; B: CXCL8; C: CXCL9; D: CXCL10; E: CCL1; F: IL-6; G: IL-10; H: IL-17A; I: CCR8; J: gp130; K: IL-10RA; L: IL-17RA) Bars show means \pm SEM from at least 3 independent experiments. * significantly different from the naïve (Student's paired t-test; $p<0,05$ ) Pink: iDC; orange: $\mathrm{mDC}$ ) 


\section{PGN stimulation has distinct effect on the relative gene expression of TNF- $\alpha$ and the} members of the TNF- $\alpha$ family

TNF- $\alpha$ together with IL- $1 \beta$ and IL-6 is an acute-phase protein, which has pivotal role in the early immune response against invading pathogens. For example we demonstrated that Candida parapsilosis infection results in robust up regulation of TNF- $\alpha$ as soon as 1 hour after the infection [51].

QRT-PCR data demonstrated that in both iDCs and mDCs prolonged PGN stimulation resulted in robust gene expression down regulation of TNF- $\alpha$ as compared with $\mathrm{N}+\mathrm{PGN}$ samples (Figure 11A). In order to validate this result on translational level we carried out secreted TNF- $\alpha$ measurement by ELISA (the sensitivity of the kit is between $0-10000 \mathrm{pg} / \mathrm{ml}$ ) from cell culture supernatants 24 hours post-second PGN treatment in order to give enough time for protein translation. ELISA measurement supported the relative gene expression data (Figure 11F): in iDCs, PGN stimulation resulted in significantly elevated secreted TNF- $\alpha$ level compared with naïve cells. Because recombinant TNF- $\alpha$ was used to generate mDCs (see Materials and methods) it is not surprising that in mDCs enhanced secreted TNF- $\alpha$ level was detected in cell culture supernatants from naïve cells (average secreted TNF- $\alpha$ level: $2661,3966 \mathrm{pg} / \mathrm{ml}$ ). It is important to note here that neither single (average secreted TNF- $\alpha$ level: $2796,28 \mathrm{pg} / \mathrm{ml}$ ) nor prolonged PGN stimulation (average secreted TNF- $\alpha$ level: 2671,58 pg/ml) had impact on secreted TNF- $\alpha$ level in mDCs.

The relative gene expression of TNFSF15 (also known as TL1A; Figure 11D) was significantly induced after PGN stimulation in iDCs, although it is not fully understood to which pathogens TNFSF15 has evolved to. Thus far, few infectious pathogens has been tested in TNFSF15 deficient animal models [56] although we have a much better understanding of the pathological role of TNFSF15 in autoimmune diseases such as psoriasis [57], in which the authors demonstrated strong nuclear immunopositivity in psoriatic skin samples than healthy controls.

In case of TNFAIP6 (also known as TSG6; Figure 11C) the identical relative gene expression pattern was detected as for TNFSF15 (Figure 11D) in iDCs; as PGN stimulation resulted in robust relative gene expression up regulation. In $\mathrm{mDCs}$, we also demonstrated the PGN-derived up-regulation, however the degree of the up regulation 
was less prominent as in iDCs. It is important to note that TNFAIP6 is a multifunctional protein [58] which is able to interact with the members of the extracellular matrix [59]. Previous reports demonstrated that the enhanced TNFAIP6 level is a response to TNF- $\alpha$ and IL-1 stimulation and it has essential role in extracellular matrix remodeling, thus it emphasizing its role in autoimmune diseases [58].

During the elimination of pathogens/antigens immune pathogenesis is a common side effect of extended inflammation. To maintain the tissue homeostasis and the transient nature of the immune response inflammation must be strictly regulated. Recent studies demonstrated that two classes of molecules are required for this process. The first class limits the strength of immune activation, these include inhibitory cytokines, negative transcription factors and the negative regulators of the TLR signaling [60], [61]. The second class includes those molecules which are involved in programmed cell death such as Fas, Bim, Bax and caspases [60], [62]. In order to gain insight into the expression pattern of negative regulators, we next analyzed the impact of the PGN stimulation on the relative gene expression pattern of TNFAIP3 and TNFAIP8.

The relative gene expression pattern of TNFAIP3 (also known as A20; Figure 11C) was similar to TNF- $\alpha$, as prolonged PGN stimulation resulted in significant relative gene expression down regulation in both iDCs and mDCs. In contrast to TNF- $\alpha$ TNFAIP3 is an important negative regulator of inflammatory response. This was demonstrated by the fact that TNFAIP3 deficient mice die early after the birth due to serious multi-organ inflammation [63], furthermore, gene targeting of TNFAIP3 in different cell types was shown to be associated with chronic inflammation and autoimmunity [64], [65, 66] .

In contrary with the previously mentioned members of the TNF- $\alpha$ superfamily, the relative gene expression of the negative regulator TNFAIP8 (also known as TIPE2; Figure 11E) was significantly down regulated after PGN stimulation in both iDCs and mDCs as compared with naïve cells. Moreover, in T+PGN samples a more robust gene expression down regulation was detected than in N+PGN samples. Recent reports demonstrated that TNFAIP8 is predominantly expressed in immune cells especially in monocytes, macrophages and $\mathrm{T}$ cells [67], [68], [69], where it negatively regulates $\mathrm{T}$ cell receptor (TCR) and TLR signaling. The absence of TNFAIP8 expression results in hyperresponsiveness of TCR and TLR activation and enhanced pro-inflammatory cytokine production. This is in line with our findings that prolonged PGN stimulation resulted in 
significant relative gene expression up regulation in case of CXCL8 (Figure 10B), CCL1 (Figure 10E), IL-6 (Figure 10F) and IL-17A (Figure 10H) as compared with naïve cells.

The investigation of the expression pattern of the members of the TNF- $\alpha$ superfamily strongly suggests that PGN stimulation results in the significant induction of the proinflammatory mediators, yet we demonstrated the tolerizeable nature of TNF- $\alpha$ and TNFAIP3. In contrary with the pro-inflammatory effectors, PGN treatment significantly down regulated the relative gene expression of TNFAIP8 compared with naïve cells.
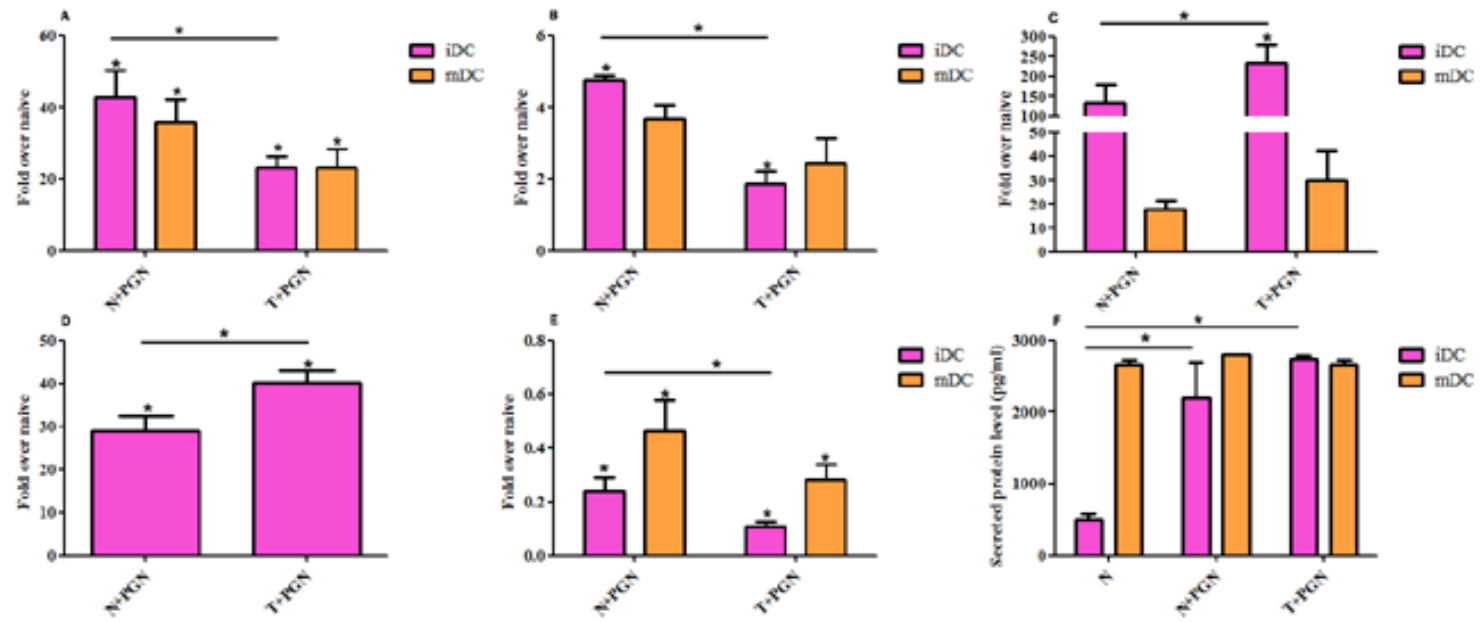

Figure 11. PGN treatment has opposite effect on the relative gene expression of TNF- $\alpha$ and the members of TNF- $\alpha$ superfamily in iDCs and mDCs, respectively. (A: TNF- $\alpha$; B: TNFAIP3 / A20; C: TNFAIP6 / TSG6; D: TNFSF15 / TL1A; E: TNFAIP8 / TIPE2; F: secreted TNF- $\alpha$ level from cell culture supernatants). Bars show means \pm SEM from at least 3 independent experiments. * significantly different from the naïve (Student's paired $t$ test; $p<0,05$ ). Pink: iDC; orange: $\mathrm{mDC}$.

\section{SOCS proteins have function in the regulation of PGN induced inflammation}

The TLR-dependent activation of the innate immunity results in the initiation of a pro-inflammatory program to defend the host against the invading pathogen. As pointed out, communication between innate and adaptive immune system through cytokines and chemokines is essential for the fully functional immune response. The cytokine mediated signal transduction must be carefully controlled to avoid the host from immunepathologic side effects and to maintain the transient nature of the immune response [70]. Beside the previously mentioned negative regulators of the innate immunity from TNF- $\alpha$ superfamily, suppressor of cytokine signaling (SOCS) proteins have been identified as an inducible inhibitors of cytokine signaling and have these molecules have pivotal role in the limitation of the inflammatory responses [71]. 
Beside the down regulation of the immune response, SOCS proteins had also been shown to interfere with DC physiology. Hanada et. al. demonstrated that SOCS1 knockout DCs showed aberrant activation of the adaptive immune system which finally resulted in the induction of autoimmunity [72]. In our experimental model we demonstrated the tolerizeable nature of SOCS1 in iDCs (Figure 12A; pink bars). Our findings strongly suggest that the down regulation of SOCS1in iDCs after prolonged PGN stimulation results in the massive induction of cytokine production which may lead to the development of autoimmune diseases.

Similarly with SOCS1, the tolerizeable nature of SOCS2 was demonstrated in iDCs after prolonged PGN stimulation (Figure 12B; pink bars). Uniquely from SOCS proteins the relative gene expression of SOCS2 was down regulated in mDCs after single PGN treatment compared with naïve cells although the down regulation was not significant $(\mathrm{p}=0,1737)$ (Figure 12B; orange bars). Moreover, in $\mathrm{T}+\mathrm{PGN}$ samples we detected a more robust gene expression down regulation than in N+PGN samples. It is important to note here that Posselt and his colleagues demonstrated that in primary human monocytederived DCs, SOCS2 shows a time-delayed expression pattern after LPS stimulation [73]. In that report Posselt et. al also demonstrated that the silencing of SOCS2 results in enhanced cytokine production, especially in case of IL-10 and IL-1 $\beta$ [73]. Our results corroborate these findings as we detected enhanced relative gene expression of IL-10 after PGN stimulation (Figure 10G).

We also examined the impact of single or prolonged PGN stimulation on the relative gene expression pattern of SOCS3 which is one of the most potent suppressor of cytokine signaling beside SOCS1 [74]. In both iDCs and mDCs PGN stimulation resulted in enhanced relative gene expression level of SOCS3 compared with naïve cells.

The investigations of the expression of SOCS genes with both SAGE-Seq and QRTPCR suggest that the enhanced relative gene expression level of SOCS1 and SOCS3 may be responsible for the down regulation of pro-inflammatory effector molecules in mDCs which, among others, prevents the host against the harmful immune-pathologic side effects of extended inflammation. In contrary, the decreased relative gene expression level of SOCS1 and SOCS2 in iDCs after prolonged PGN stimulation strongly explains the enhanced production of inflammation-related effector molecules and support our 
hypothesis that ex vivo PGN stimulated iDCs can be used to model the physiology of IFN-primed psoriatic DCs.
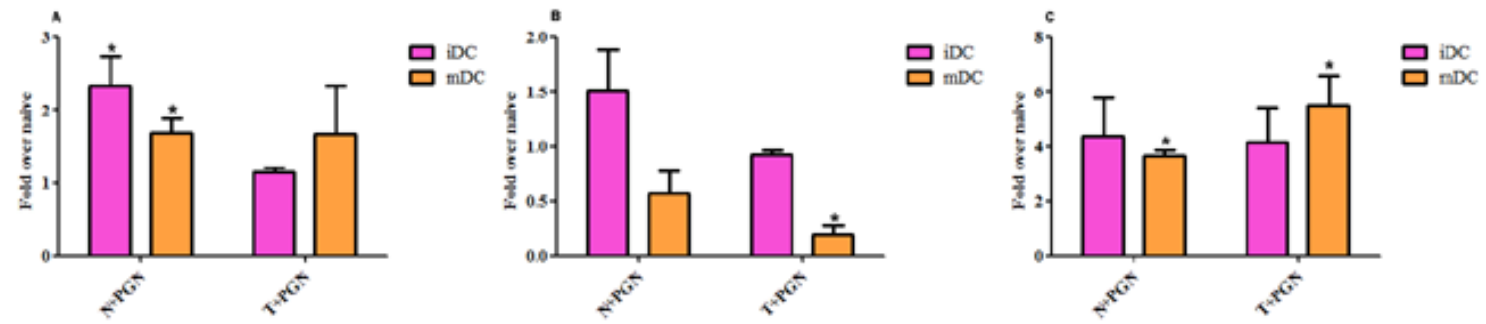

Figure 12. The members of SOCS family have function in the PGN induced inflammation (A: SOCS1; B: SOCS2; C: SOCS3) Bars show means \pm SEM from at least 3 independent experiments. * significantly different from the naïve (Student's paired t test; $\mathrm{p}<0,05$ ) Pink: iDC; orange: mDC.

\section{Tryptophan deprivation has possible role in the control of Staphylococcal infection}

Beyond the elevated cytokine expression and the induction of the adaptive immune response, tryptophan deprivation is another possible mechanism to control 1) pathogenic infections [75] and 2) the maintenance of self tolerance [76]. For these, a potential mechanism is the over expression of the tryptophan catabolizing enzyme, indolamine 2,3dioxigenase (IDO). The enhanced IDO activity suppresses effector $\mathrm{T}$ cell responses, promotes regulatory $\mathrm{T}$ cell differentiation and activation and inhibits IL- 6 production by DCs [77] [78].

Thus, and based on the SAGE-Seq experiments in which we detected the induction of tryptophan breakdown, we tested the impact of PGN stimulation on the gene expression of IDO (Figure 13B) and kynureninase (Kynu; Figure 13A) which are both involved in tryptophan degradation [79]. The relative gene expression of IDO was significantly up regulated in both iDCs and $\mathrm{mDCs}$ in $\mathrm{N}+\mathrm{PGN}$ samples and a more pronounced gene expression up regulation was detected in both cell types after prolonged PGN stimulation. Single PGN stimulation resulted in significant gene expression up regulation in iDCs and mDCs in case of Kynu (Figure 13B) compared with naïve cells. After prolonged PGN stimulation a more robust relative gene expression up regulation was detected as compared with both naïve and N+PGN samples in iDCs. In contrary with iDCs, the second PGN stimulation had no impact on the relative gene expression of Kynu in $\mathrm{mDCs}$ (Figure 13A; orange bars). 
These data strongly suggest that the over expression of tryptophan catabolizing enzymes has role in the control of acute and more interestingly in persistent Staphylococcal infection in DCs.
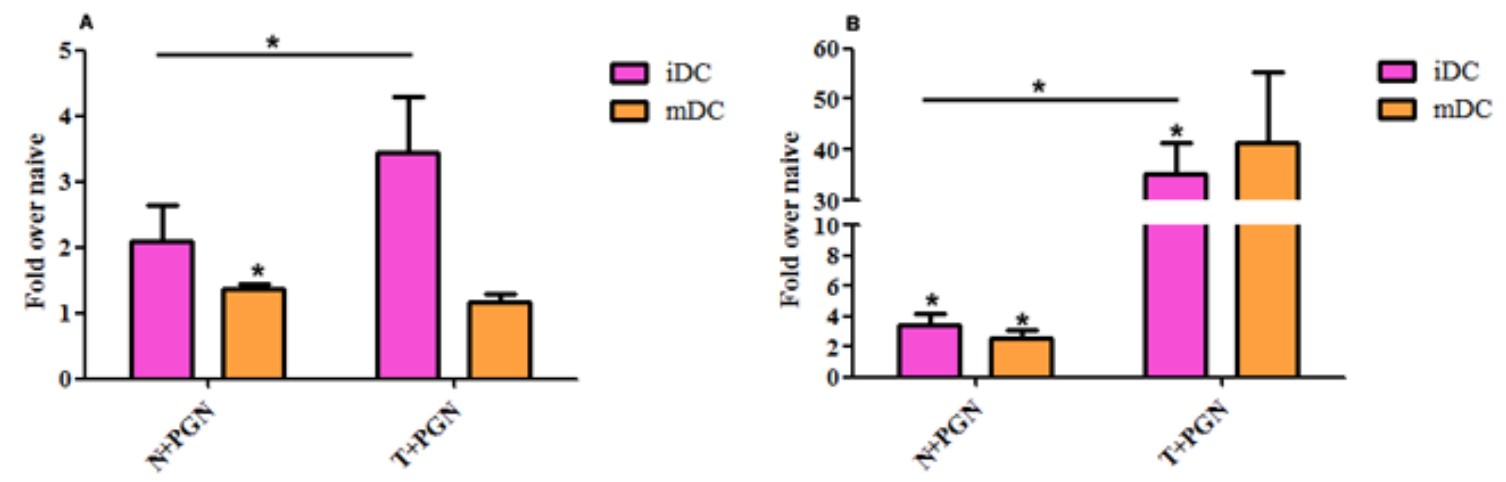

Figure 13. PGN stimulation resulted in elevated relative gene expression of enzymes involved in tryptophan catabolism (A: kynureninase, Kynu; B: indolamine 2,3-dioxygenase, IDO). Bars show means \pm SEM from at least 3 independent experiments. * significantly different from the naïve (Student's paired $t$ test; $\mathrm{p}<0,05)$. Pink: iDC; orange: $\mathrm{mDC}$.

\section{PGN stimulation induces cell cycle arrest and resistance to apoptotic process}

The strict regulation of cell division cycle has pivotal role in the maintenance of tissue homeostasis and the protection against cancer. As cyclins and cyclin-dependent kinases have pivotal role in the transition of different phases of cell cycle we examined the impact of PGN treatment on the gene expression of cyclin B2 (CycB2; Figure 14A) which is involved in G2-M transition and cyclin D1 (CycD1; Figure 14B) which has central role in G1-S transition [80].

SAGE-Seq and QRT-PCR demonstrated that single or prolonged PGN stimulation resulted in relative gene expression down regulation in case of $\mathrm{CycB} 2$ in iDCs (Figure 14A; pink bars) and in case of CycD1 (Figure 14B) in both iDCs and mDCs. In mDCs we demonstrated the tolerizeable capacity of CycB2 (Figure 14A; orange bars): in N+PGN samples moderate gene expression up regulation was detected as compared to naïve cells, however prolonged PGN stimulation resulted in gene expression down regulation compared to N+PGN samples.

The induction of apoptotic processes has important role in the maintenance of the transient nature of the immune response [60], [61]. We examined the impact of PGN stimulation on the relative gene expression of two genes involved in the regulation of cell 
fate and apoptosis. Fas-associated protein with death domain (FADD, Figure 14C) has essential role in the activation of the caspase cascade by cleaving pro-caspase 8 during extrinsic apoptotic pathway. In both iDCs and mDCs single and prolonged PGN stimulation resulted in significant gene expression down regulation compared with naïve cells although we did not find any further difference in the gene expression of FADD between $\mathrm{N}+\mathrm{PGN}$ and $\mathrm{T}+\mathrm{PGN}$ samples.

We also examined the impact of single and prolonged PGN stimulation on the relative gene expression of transforming growth factor $\beta$ (TGF- $\beta$; Figure 14D). In both iDCs and mDCs PGN stimulation resulted in significant relative gene expression down regulation as compared to naïve cells, although the relative gene expression of TGF- $\beta$ was up regulated in $\mathrm{T}+\mathrm{PGN}$ cells than $\mathrm{N}+\mathrm{PGN}$ samples in iDCs $(\mathrm{p}=0,0042)$ (Figure 14D; pink bars).

Taking together both SAGE-Seq and QRT-PCR experiments suggest that, acute and persistent Staphylococcal infections decrease cell division cycle by down regulating the relative gene expression level of cyclins which have central role in this process. Moreover in accordance with SAGE-Seq results, the reduced expression level of pro-apoptotic genes suggests the induction of pro-survival mechanisms which may lead to the elimination of invading pathogens.
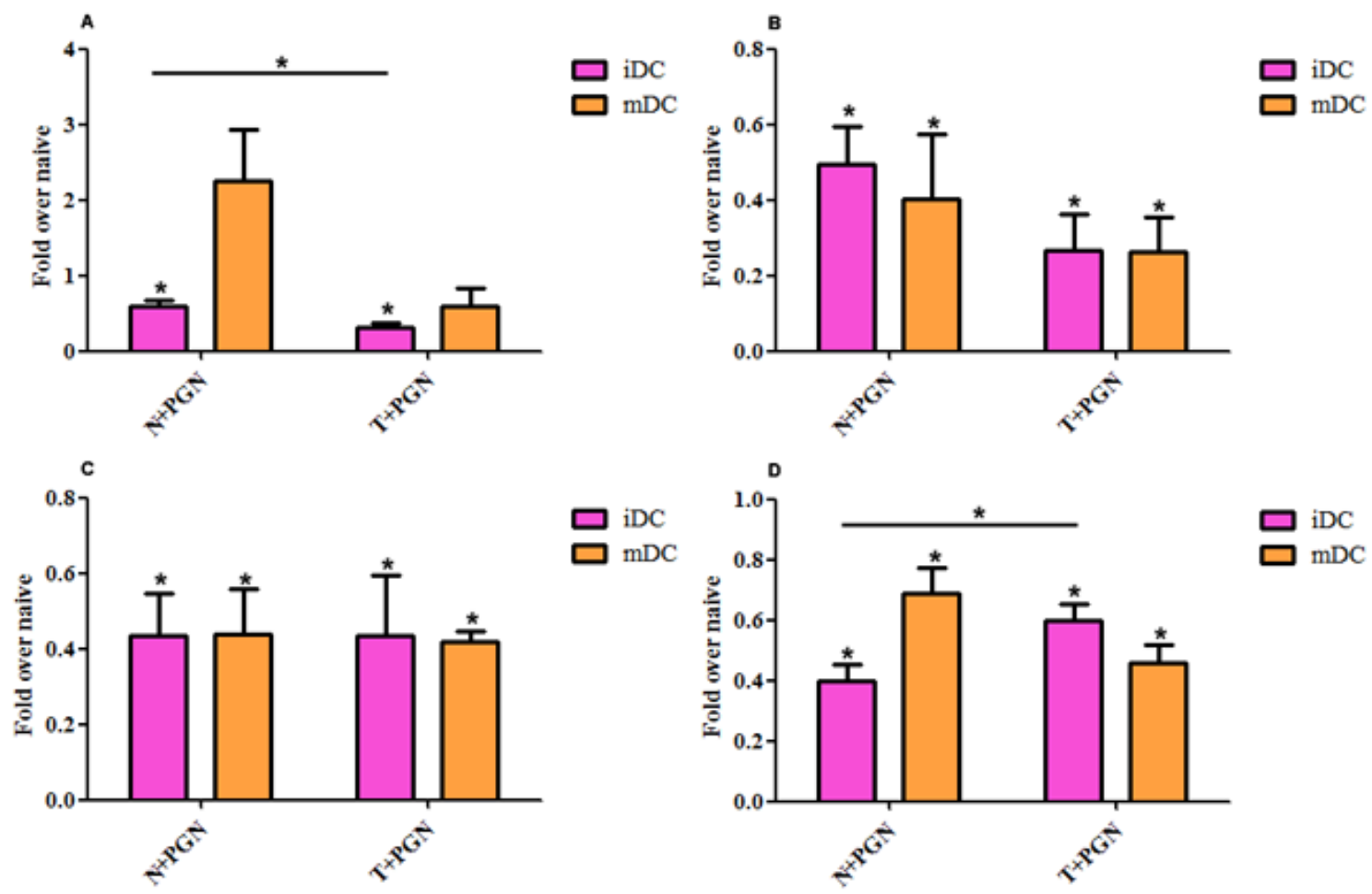
Figure 14. PGN challenge results in cell cycle arrest and resistance to apoptotic process (A: cyclin B2, CycB2; B: cyclin D1, CycD1; C: Fas-Associated protein with Death Domain, FADD; D: transforming growth factor $\beta$, TGF- $\beta$ ). Bars show means \pm SEM from at least 3 independent experiments. * significantly different from the naïve (Student's paired t test; $* \mathrm{p}<0,05$ ). Pink: iDC; orange: mDC.

\section{The relative gene expression of the members of TNF- $\alpha$ super family from psoriatic}

\section{samples show strong correlations with our in vitro model}

Pro and anti-inflammatory members of the TNF- $\alpha$ superfamily maintain critical balance during acute and persistent Staphylococcal infection to successfully eliminate invading pathogens and to prevent the host against the harmful side effects of uncontrolled inflammation (Figure 11). Although the pathogenesis of psoriasis has not been fully understood yet, the immunological basis of this disease has been demonstrated [81]. Although it is well known that the enhanced level of TNF- $\alpha$ has pivotal role in the pathogenesis of psoriasis [82], [83], little is known about the expression pattern of the other members of the TNF- $\alpha$ superfamily in this autoimmune disease. In case of TNFSF15 a previous report demonstrated strong nuclear immunopositivity in psoriatic skin samples, in contrast, TNFSF15 was absent in healthy skin samples [57]. In order to determine the relative gene expression pattern of TNFAIP3, TNFAIP6 and TNFAIP8 in plaque-type psoriasis we performed QRT-PCR experiments on psoriatic non-leisonal and lesional dermal and epidermal samples. As controls, healthy skin biopsy samples were used.

First, we examined the relative gene expression pattern of TNF- $\alpha$ (Figure 15A). We found that the relative gene expression level of TNF- $\alpha$ was up regulated in psoriatic nonlesional epidermal and dermal samples compared with healthy samples (Figure 15A). Furthermore, in lesional samples a more robust up regulation was detected than in nonlesional samples. As these data corroborate earlier findings [84] we used these samples for further experiments.

In accordance with PGN stimulated DCs (Figure 11C) the relative gene expression of TNFAIP6 was significantly up regulated in psoriatic non-lesional and lesional epidermal samples compared with healthy skin samples ( Figure 15C; blue bars). In non-leisonal dermal samples significant gene expression down regulation was detected as compared to healthy skin samples, however in lesional samples robust gene expression up regulation was detected (Figure 15C; green bars). 
In contrary with the pro-inflammatory mediators the anti-inflammatory effector molecules, TNFAIP3 (Figure 15B) and TNFAIP8 (Figure 15D) were both down regulated in psoriatic non-lesional and lesional epidermal and dermal samples as compared to healthy controls. It is important to note that these results show strong correlations with the results from PGN stimulated DCs (Figure 11B and Figure 11E, respectively).

To summarize these results we can conclude that beside the enhanced level of TNF$\alpha$, the elevated expression of TNFAIP6 also has important role in the maintenance of chronic inflammation which is characteristic for psoriasis. Furthermore, the down regulation of TNFAIP3 and TNFAIP8 strongly suggest that braking mechanisms of inflammation are disturbed which may also explain chronic inflammation.

As the results obtained from the investigation of psoriatic skin biopsy samples demonstrate strong correlation with the results of PGN stimulated DCs we also compared the relative gene expression pattern of other inflammation-related effector molecules in plaque-type psoriasis and the ex vivo PGN stimulated DCs. It is well known that the enhanced level of Th1 and Th17 cytokines have essential role in the pathogenesis of psoriasis by increasing the number of effector T lymphocytes in the skin. As we detected significant induction of IL-6 (Figure 10F), IL-17A (Figure 10H) and CXCL8 (Figure 10B) in DCs after single or prolonged PGN stimulation and considering that elevated level of CCL1 (Figure 10E) is also characteristic for psoriasis [85] we conclude that PGN stimulated DCs could be used to model the characteristics and the function of IFN-primed DCs in psoriasis. 

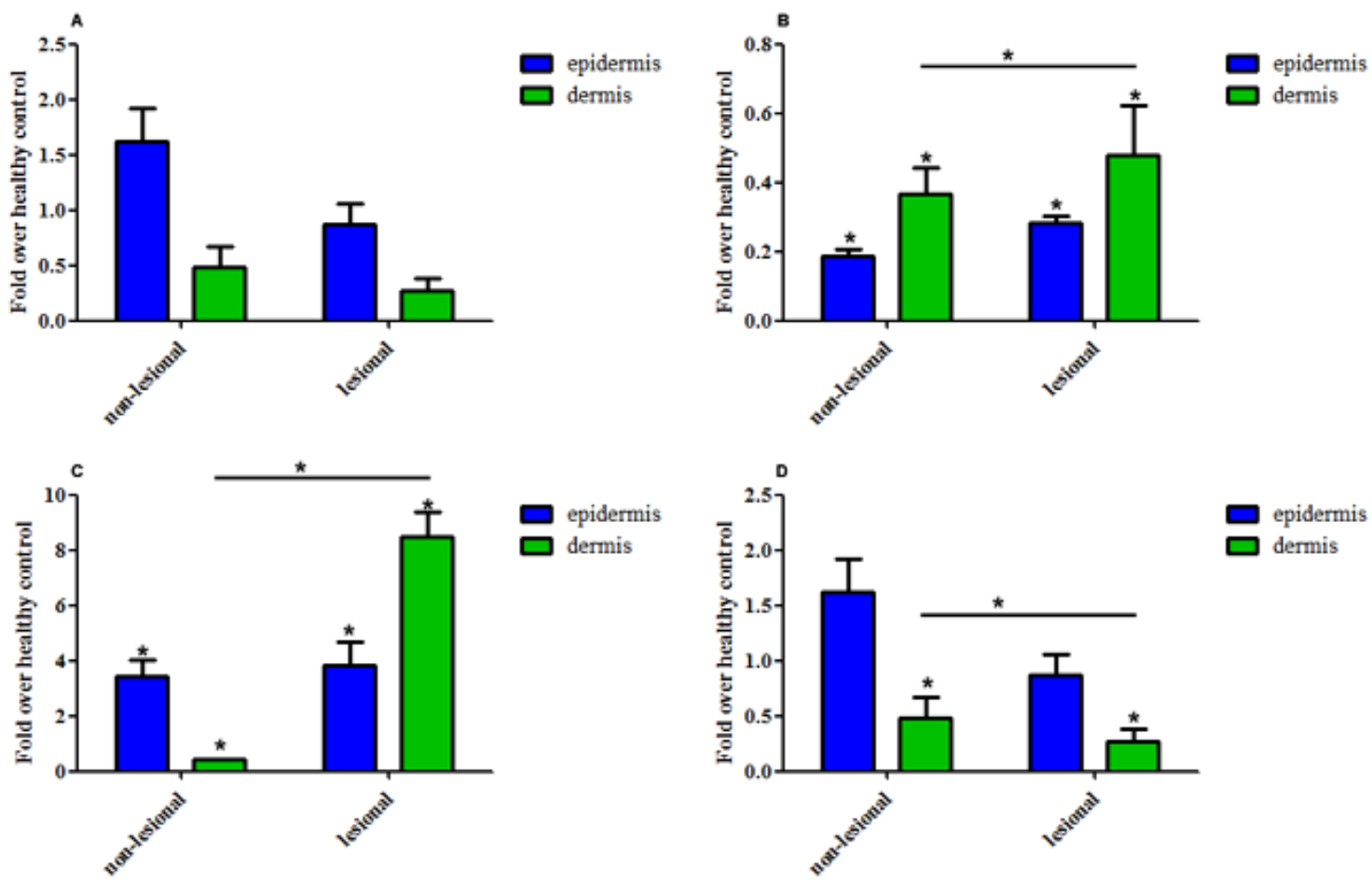

Figure 15. Elevated pro inflammatory and decreased anti- inflammatory cytokine expression was detected in psoriatic non-lesional and lesional dermis and epidermis (A: TNF- $\alpha$; B: TNFAIP3 / A20; C: TNFAIP6 / TSG6; D: TNFAIP8 / TIPE2). Bars show means \pm SEM from 3 individuals. * significantly different from age and gender matched healthy controls (Student's paired $\mathrm{t}$ test; * $\mathrm{p}<0,05$ ). Blue: epidermis; green: dermis

\section{TNF- $\alpha$ blockade down regulates pro inflammatory cytokines at relative gene}

\section{expression and secreted protein level in T+PGN samples}

Beside conventional treatment strategies, TNF- $\alpha$ blocking antibodies became the most common therapeutic approaches to cure psoriasis. Thus, and based on our results which demonstrate that iDCs after prolonged PGN stimulation show strong correlations with psoriatic DCs we aimed to test the impact of TNF- $\alpha$ deprivation at cellular level. For this, soluble chimeric monoclonal anti-TNF- $\alpha$ antibody (Remicade, infliximab) was added to monocytes in parallel with differentiation procedure as described in materials and methods. Although Remicade has a long half-life, to block the PGN induced de novo synthesized TNF- $\alpha$ we also added anti-TNF- $\alpha$ antibody in parallel with PGN treatment (Figure 6).

First we monitored the impact of Remicade treatment on the relative gene expression pattern of TNF- $\alpha$ (Figure 16A). Single PGN stimulation in combination with Remicade treatment resulted in significant relative gene expression up regulation compared with 
naïve cells (average fold change: 73,36). Similar with only PGN stimulated iDCs (average fold change:36,58), prolonged PGN stimulation with Remicade treatment resulted in significant relative gene expression down regulation as compared with N+PGN samples (average fold change: 16,8). In N+PGN samples Remicade treatment resulted in more robust relative gene expression up regulation (average fold change 73,36) than only single PGN stimulated cells (average fold change: 36,58 ). In T+PGN samples TNF- $\alpha$ block

ade had no impact on the average fold change as compared with only PGN stimulated samples.

Single or prolonged PGN stimulation resulted in significant relative gene expression up regulation in case of IL-6 (Figure 16B) compared with naïve cells (average fold change: 108,32 and 208,04, respectively). Interestingly, in T+PGN samples Remicade treatment resulted in robust relative gene expression down regulation of IL-6 compared with prolonged PGN stimulated iDCs (average fold change: 76,93 versus 208,04, respectively, $\mathrm{p}=0,1172$ ).

As mentioned earlier, PGN stimulation results in the up regulation of the relative gene expression of CCL1 (Figure 16C; average fold change: 5,69) and a more robust relative gene expression up regulation was detected after prolonged PGN stimulation (average fold change: 99,13). Importantly, Remicade treatment resulted in relative gene expression down regulation in $\mathrm{N}+\mathrm{PGN}$ samples (average fold change: 0,$6 ; \mathrm{p}=0,1157$ ). Although Remicade treatment in $\mathrm{T}+\mathrm{PGN}$ samples moderately up regulated the relative gene expression of CCL1, the average fold change was significantly less than only PGN treated iDCs. To analyze this result at secreted protein level, ELISA measurement from cell culture supernatants was performed (Figure 16D). ELISA measurements strongly supported our QRT-PCR results: the blockade of secreted TNF- $\alpha$ significantly down regulated secreted CCL1 level in T+PGN samples compared with iDCs after prolonged PGN stimulation.

These data strongly suggest that the blockade of secreted TNF- $\alpha$ has significant impact on the relative gene expression pattern of other cytokines. Corresponding to previous articles [86], [87], Remicade treatment robustly down regulates the relative gene expression of IL-6 which strongly suggest the fact that IL-6 together with TNF- $\alpha$ has central role in inflammatory responses. It has not been published yet, that Remicade 
treatment significantly decreased the relative gene expression and the secreted protein level of CCL1 as compared with only PGN stimulated iDCs. Our previous findings at both relative gene expression and secreted protein level strongly suggest that ex vivo PGN stimulated DCs are identical with IFN- $\alpha$ primed psoriatic DCs, moreover, ex vivo PGN stimulated iDCs could be used to model the physiology of IFN- $\alpha$ primed psoriatic DCs. Furthermore, beside TNF- $\alpha$, other inflammation-related effector molecules, such as IL-6, CCL1 and TNFAIP6 have pivotal role in the pathogenesis of psoriasis. The results of secreted TNF- $\alpha$ blockade massively suggest that these cytokines can be used as a target gene/protein to treat plaque-type psoriasis.
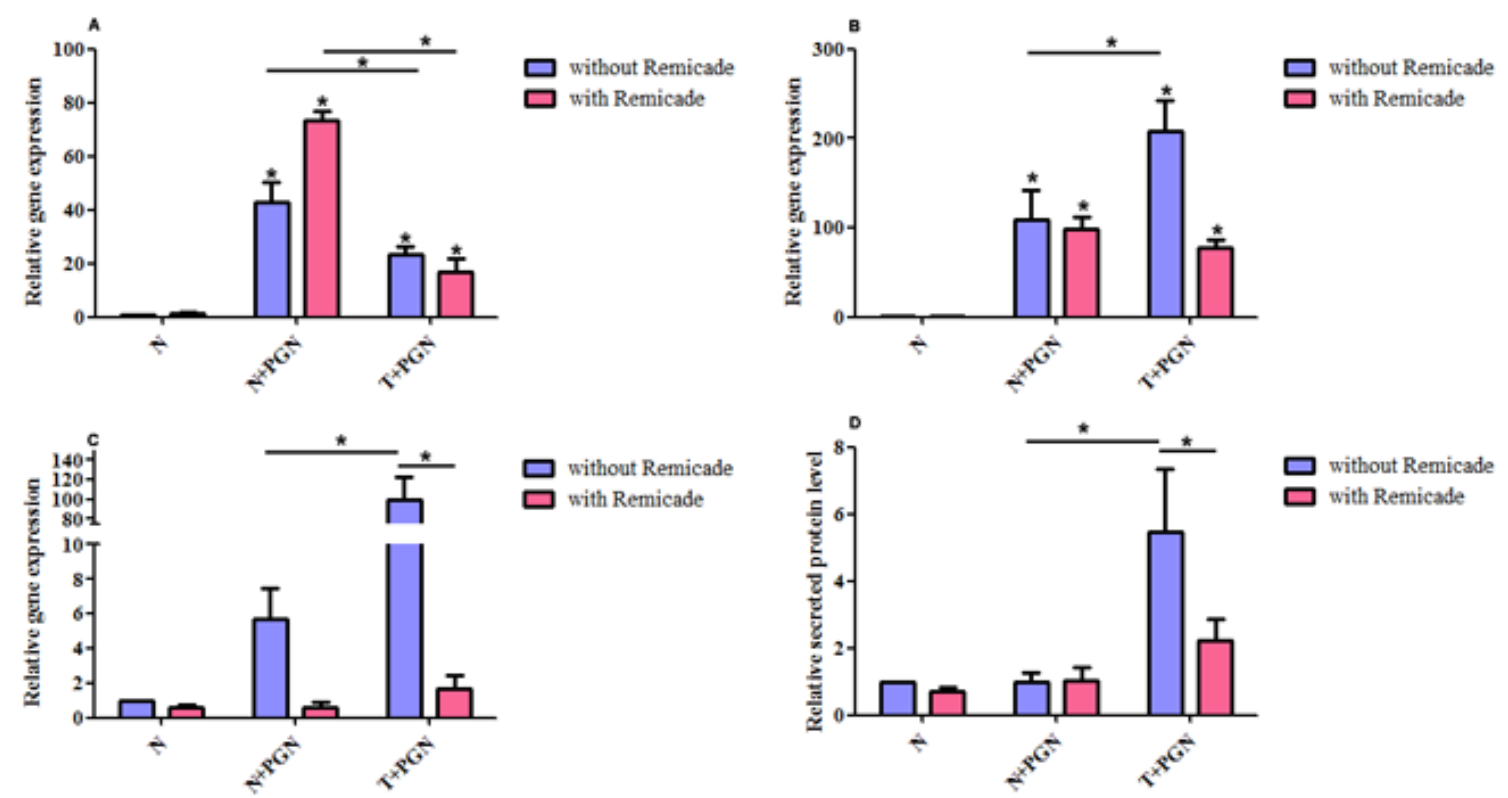

Figure 16. TNF- $\alpha$ deprivation results significant impact on the expression pattern of pro inflammatory mediators in the presence of $S$. aureus derived PGN at relative gene expression and secreted protein level, respectively. (A: the relative gene expression of TNF- $\alpha, \mathrm{B}$ : the relative gene expression of IL-6; C: the relative gene expression of CCL1; D: secreted protein level of CCL1) Bars show means \pm SEM from at least 3 independent experiments. * significantly different (Student's paired t test in relative gene expression studies and One -Way ANOVA following Neuman-Keuls post-hoc test in secreted protein measurements; * p<0,05) Purple: without Remicade; pink: with Remicade 


\section{Discussion}

In mammals DCs have pivotal role in orchestrating innate and adaptive immune response against impending pathogens. For this, they have sentinel function at the periphery by sensing and taking up pathogens/antigens [6]. Pathogen/antigen uptake initiates maturation processes which transform immature DCs into $\mathrm{mDCs}$ that are professional antigen presenting cells (APCs). Professional APCs present pathogenderived antigens through their MHC II molecules to naïve $\mathrm{T}$ lymphocytes at the proximate lymph nodes and initiate adaptive immune response [88], [24].

\section{PGN stimulation and re-stimulation has appreciable impact on the gene expression}

\section{profile of primary human iDCs}

In order to get a global view on the alterations caused by single or prolonged PGN stimulation on iDCs, SAGE-Seq experiments were carried out. Bioinformatics analysis of SAGE-Seq results confirmed our hypothesis that the TLR2 stimulation with its respective ligand has strong impact on iDCs, as the gene expression of as many as 5411 genes were significantly changed (Figure 8). In this study we mainly focused on those 566 genes which expression patterns were uniquely different between single or prolonged PGN stimulation, because they - presumably - represent the differences between acute and persistent infection.

Pathway analysis was carried out to characterize the potential relevance of the alterations caused by single or prolonged PGN stimulation. Both BioProc and Kegg pathway analysis strongly suggest that iDCs maintain critical balance between inflammation and tolerance in order to maintain the transient nature of the immune response and to protect the host from immune pathologic side effects caused by extended inflammation. In contrary, PGN stimulation resulted in the down regulation of numerous members of the cell cycle and energy production pathways, which supports the fact that antigen challenge resulted in DC maturation characterized by functional changes rather than the numeral expansion of iDCs. It is also important to note that PGN stimulation results in the induction of autoimmune inflammatory disease pathways, such as systemic lupus erythematosus or autoimmune thyreoid disease. 
The relative gene expression profile of pro-inflammatory mediators after single or prolonged PGN stimulation show strong correlations with autoimmune diseases

Chemokines are small secreted proteins which have pivotal role in the migration and the organ specific homing of distinct leukocyte subsets in vivo [89], [90]. In accordance with SAGE-Seq results QRT-PCR validation demonstrated that single or prolonged PGN stimulation significantly up regulates the relative gene expression of the majority of proinflammatory cytokines/chemokines, such as CXCL8 (Figure 10B), CCL1 (Figure 10E), IL-6 (Figure 10F) and IL-17A (Figure 10H). Beside their central role in pathogen clearance, the robust induction of these cytokines is also characteristic for autoimmune diseases. It is not surprising that enhanced IL-17A level was detected in iDCs, because this cytokine is essential in $\mathrm{T}$ cell dependent immune response, and it was first described in $\mathrm{CD}^{+} \mathrm{T}$ lymphocytes [91]. Furthermore, this cytokine is able to induce IL-6, CXCL8 and GM-CSF production by fibroblasts, and enhanced CXCL8 and TNF- $\alpha$ production by macrophages [92]. Moreover, the role of IL-17A is not limited to the immune defense against extracellular pathogens [93], [94], [95], since elevated IL-17A level was detected in samples from inflammation-related diseases, such as synovial fluids of patients with rheumatoid arthritis [96], colon biopsies from inflammatory bowel disease [97], and in affected skin subjects with nickel induced contact dermatitis or psoriasis [98]. Based on the model of the pathogenesis of psoriasis described by Farkas and Kemény [36] it is not surprising that ixekizuimab (humanized IgG4 monoclonal antibody against IL-17A) is successfully used to treat moderate to severe plaque type psoriasis [44].

Identically with the previously mentioned chemokines, SAGE-Seq data evidenced significant tag enrichment after single or prolonged PGN stimulation in case of IL-23. The expression of this cytokine can be activated by IL- 6 and TGF- $\beta$ and it is involved in the development of Th17 cells [99], [100], [101], [102]. Other reports demonstrated that the relative gene expression of IL-23 is significantly increased in psoriatic lesional epidermis compared to non-lesional biopsy samples, moreover, the secreted IL-23 level by monocytes and dendritic cells is unusually high in psoriatic patients [103], [104]. Beside psoriasis, enhanced IL-23 level is also characteristic for other autoimmune diseases, such as systemic lupus erythematosus [105], [106], rheumatoid arthritis [107], or inflammatory bowel disease [108]. 
In contrary with these inflammation-related effector molecules, our data showed that prolonged PGN stimulation significantly down regulated the expression level of CCL18 as compared with single PGN stimulation, a phenotype that we categorized as tolerizeable expression. Enhanced CCL18 level is characteristic for atopic dermatitis where CCL18 positive dendritic-like cells are observed in the dermis [109]. In that study, Pivarcsi and his colleagues also demonstrated that PGN stimulation significantly up regulated the relative gene expression of CCL18 in Langerhans cells and intestinal-type DCs [109].

Identically with CCL18, we also demonstrated the tolerizeable expression pattern of TNF- $\alpha$ (Figure 11A and F). TNF- $\alpha$ has pivotal role in the early immune response against invading pathogens [110] thus, our findings showing the rapid induction of its gene expression after single PGN treatment is not surprising. The role of TNF- $\alpha$ is not limited to acute-phase response, it is also essential in the induction of apoptosis [111], moreover, enhanced TNF- $\alpha$ level has also been associated with a wide variety of diseases, such as cancer [112], bipolar disorder [113] and autoimmune diseases such as multiple sclerosis, systemic lupus erythematosus, psoriasis and Crohn disease [114].

Because of the diverse function of TNF- $\alpha$ and its tolerizeable expression pattern after prolonged PGN stimulation we also determined the expression pattern of the members of the TNF- $\alpha$ superfamily. Single or prolonged PGN stimulation resulted in significant relative gene expression up regulation in case of TNFSF15 (Figure 11D). This cytokine shows the most conserved architecture compared to TNF- $\alpha$ based on the presence of conserved subdomains [115]. As TNFSF15 is a potent inducer of the effector mechanisms of T lymphocytes [116] it is not surprising that it has pivotal role in the pathogenesis of Crohn disease [117], [118] and psoriasis [57].

The tolerizeability of CCL18 together with CXCL9 (Figure 10C), CXCL10 (Figure 10D) and TNF- $\alpha$ (Figure 11A and F) strongly suggest the induction of tolerogenic mechanisms rather than inflammation in order to prevent the host against the side effects of extended inflammation. Furthermore, the enhanced expression levels of those genes which are involved in the pathogenesis of psoriasis strongly support our hypothesis that prolonged PGN stimulation not only models persistent infection but it is a useful model to investigate psoriatic dendritic cells. This is particularly important since it is almost impossible to separate Langerhans cells from psoriatic skin samples, thus the 
characterization of the gene expression pattern of these cells was only possible using $e x$ vivo in situ hybridization.

\section{Tryptophan deprivation has central role in the control of Staphylococcal infection}

\section{and the induction of autoimmune inflammatory diseases}

In this study we demonstrated that PGN stimulation resulted in significant relative gene expression up regulation of IDO (Figure 13B) and Kynu (Figure 13A) which are involved in tryptophan breakdown [79] (Figure 17).

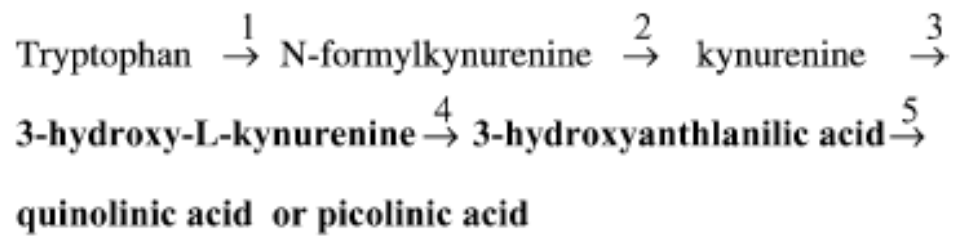

1. Indoleamine 2,3-dioxygenase (IDO)

2. N-formylkynurenine formamidase

3. Kynurenine 3-monoxygenase

4. Kynureninase

5. 3-hydroxyanthranilate oxygenase

Figure 17. Tryptophan degradation pathway [79]

More than ten years ago it was demonstrated that the up regulation of typtophan breakdown confers antiparasitic and antimicrobial effector functions of macrophages, monocytes, fibroblasts and epithelial cells [75]. Furthermore, tryptophan deprivation interferes with Chlamydia trachomatis (Virok, Filkor et al unpublished data), which is a tryptophan auxotroph bacteria [119], [120].

The induction of tryptophan catabolism is not limited to the elimination of invading pathogens, it also has central role in the inhibition of $\mathrm{T}$ cell proliferation [121], [122]. Upon stimulation with Th1 cytokines such as IFN- $\gamma$ and TNF- $\alpha$ the expression of IDO can be induced in PBMCs [123], [124]. Accordingly, it is not surprising that enhanced IDO activity can be detected in a wide variety of Th1 mediated inflammatory diseases such as inflammatory bowel disease [125] or psoriasis [79].

Based on these facts, the significant up regulation of the tryptophan catabolic pathway after single and prolonged PGN stimulation not only suggests the induction of the adequate immune response against invading pathogens, but it strongly supports our 
hypothesis that prolonged PGN stimulation models inflammatory diseases such as psoriasis.

\section{PGN stimulation has distinct effect on the relative gene expression of the negative regulators of inflammatory processes}

As mentioned earlier, immune response must be strictly regulated in order to protect the host against the serious side effects of extended inflammation. The mediators which are involved in this phenomenon can be divided into two groups based on their regulating capacity [60], [61], [62].

The first class of these regulatory molecules includes inhibitory cytokines and the negative regulators of the TLR dependent signaling pathway which limits the strength of immune activation. In our model, PGN stimulation resulted in significant relative gene expression up regulation of IL-10 (Figure 10G). This cytokine has pleiotropic effects in the regulation of the immune response and inflammatory processes, moreover, it has been associated with a wide variety of autoimmune and inflammation-related diseases [126]. In addition, it is also over expressed in metastatic melanoma [127] where enhanced IL-10 level has an essential role in the down regulation on the immune response against tumor cells. Our data strongly suggest that DCs maintain a critical balance between inflammation and tolerance upon Staphylococcal infection.

Because of the tolerizeable expression of TNF- $\alpha$ and its pivotal role in pathogen elimination and pathogenesis of autoimmune diseases we also determined the expression pattern of the members of TNF- $\alpha$ superfamily. Identically with the expression of proinflammatory molecule TNFSF15, significant relative gene expression up regulation was detected in case of TNFAIP6 (Figure 11C) which is a multifunctional cytokine. Our data show strong correlations with those previous reports where LPS stimulation resulted in a dose-dependent up regulation of TNFAIP6 in primary macrophages [128]. Although enhanced TNFAIP6 level was demonstrated in numerous inflammation-related diseases [58], no correlations between the relative gene expression level of TNFAIP6 and psoriasis has been reported so far.

Although TNFAIP3 (Figure 11B) is also an important negative regulator of the inflammatory response, in our model it has a similar relative gene expression pattern with TNF- $\alpha$. Our findings show strong correlations with a previous report where flagellin- 
mediated TLR5 induction resulted in abundant TNFAIP3 expression in intestinal epithelial cells which was also demonstrated in an in vivo acute colitis model in mice. This report also showed that the enhanced TNFAIP3 expression does not influence tolerance induced with flagellin restimulation [129].

In case of TNFAIP8 (Figure 11E) PGN stimulation resulted in relative gene expression down regulation in both iDCs and mDCs. In thymocytes, the down regulation of TNFAIP8 effectively protected the cells against glucocorticoid induced apoptosis [130]. Furthermore, the decreased expression level of TNFAIP8 establishes the significantly enhanced level of pro-inflammatory effector molecules such as CXCL8, IL6, CCL1 and IL-17A [67], which is in good agreement with our observations, showing a reversible expression of TNFAIP8 with the aforementioned pro-inflammatory molecules.

Beside the previously mentioned negative regulators from the TNF- $\alpha$ induced proteins, SOCS proteins also have essential role in the inhibition of extended inflammation [71], because they are feedback inhibitors of JAK/STAT signaling cascade [131]. Moreover, the absence of SOCS proteins in DCs results in the aberrant activation of the adaptive immune system which finally leads to the development of autoimmunity [72]. The tolerizeability of SOCS1 (Figure 12A) and SOCS2 (Figure 12B) strongly support their central role in the up regulation of the pro-inflammatory cytokines after single or prolonged PGN stimulation [73]. In case of SOCS3 PGN stimulation resulted in enhanced relative gene expression after single or prolonged PGN stimulation. A previous report demonstrated that the enhanced expression level of SOCS3 from psoriatic keratinocytes leads to the resistance to apoptosis [132].

The second class of the regulatory molecules is involved in the induction of programmed cell death [60]. Apoptosis is essential in the maintenance of the transient nature of the immune response and to prevent the host against cancer which can be induced by environmental triggering factors Our data demonstrated significant relative gene expression down regulation after PGN stimulation in case of Cyclin B2 (Figure 14A) and Cyclin D1 (Figure 14B). These findings strongly supported by the fact that cross-linking of TLR with its respective ligand induces maturation process which is characterized by functional differentiation of the antigen presenting cells without numeral expansion. PGN stimulation significantly reduced the relative gene expression of FADD and TGF- $\beta$ in both iDCs and mDCs. Importantly, the role of programmed cell death is not 
limited to the maintenance of tissue homeostasis, it has pivotal role in preventing the organism against the development of autoimmune diseases [133]. However, the role of FADD is not limited to the initiation of TNF-dependent apoptosis [134] it is a key factor in cell proliferation, differentiation, autophagy, genome surveillance and innate immunity [135]. Our data show strong correlations with earlier findings showing that the down regulation of FADD enhances the relative gene expression of IL-1 $\beta$, IL-6, IL-10 and TNF- $\alpha$ in mouse epidermis [136].

\section{The down regulation of the anti-inflammatory members in TNF- $\alpha$ superfamily has}

\section{essential role in the pathogenesis of psoriasis}

Beside keratinocyte hyperproliferation, extended inflammation and immune cell infiltration are also hallmarks of psoriasis [137]. The abnormalities leading to psoriasis development remain controversial; however, the cross-talk between keratinocytes and $\mathrm{T}$ lymphocytes represents a necessary step during the course of the disease [138]. Figure 18 shows the schematic illustration of the pathogenesis of plaque-type psoriasis integrating those cytokines (i.e. IL-1 $\beta$, IL-6, TNF- $\alpha$ and IFN- $\gamma$ ) and cell types which are involved in the pathogenesis of this disease [84]. According to this model dermal DCs from psoriatic lesions drive the cytokine production toward Th1 and Th17 cytokines [139], [140].

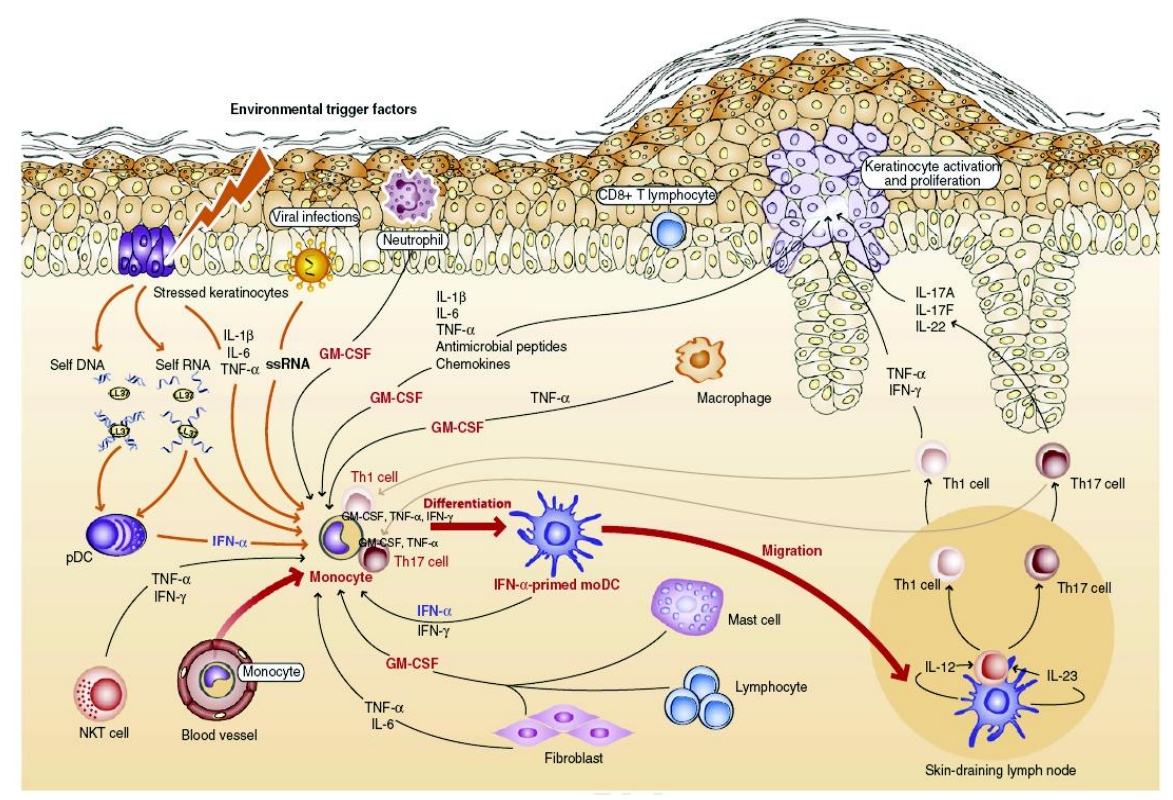

Figure 18. The brand new model of the pathogenesis of psoriasis [36] 
In accordance with the literature [82], [83] in psoriatic non-lesional and lesional skin biopsy samples significantly up regulated TNF- $\alpha$ and CXCL-8 (Szasz et al, manuscript in preparation) levels were detected. In psoriatic skin samples slightly up regulated TNFAIP6 relative gene expression level is characteristic. TNFAIP6 was first detected in fibroblasts under the stimulation of TNF- $\alpha$ [141]. This glycosaminoglycan-binding protein [142], [143] has role in experimental model of arthritis [144], [145], [146], acute myocardial infarction [147] and chemically burned rat cornea [148], [149]. These facts together with our results strongly suggest that first, TNFAIP6 is one of the key molecules in the pathogenesis of psoriasis, and, second, our model is a useful tool in mimicking the expression pattern of psoriatic DCs.

In psoriatic skin samples, the relative gene expression of TNFAIP3 was significantly down regulated as compared to healthy skin. Originally, TNFAIP3 was identified as a TNF- $\alpha$ inducible gene which functions as negative feedback inhibitor of TNF- $\alpha$ signaling [150], [151] by inhibiting NF- $\kappa \mathrm{B}$ mediated immune response [63]. Furthermore, genomewide association studies have revealed associations between TNFAIP3 and psoriasis [152], [153]. Based on these facts our data strongly suggest that the significantly decreased level of TNFAIP3 has crucial role in the maintenance of enhanced level of proinflammatory cytokines in psoriatic lesions which serve as a homing signal of infiltrating leukocytes.

TNFAIP8 is also an essential negative regulator of inflammation and immune homeostasis by down regulating the T cell receptor and TLR signaling [67] and, as it was mentioned earlier, down regulation of this gene is involved in the protection against apoptosis [130]. To the best of our knowledge we were the first who demonstrated the significant down regulation of TNFAIP8 in psoriatic dermis and epidermis at a relative gene expression level which in accordance with the literature explains the enhanced cytokine production and the decreased sensitivity to pro-apoptotic processes which is characteristic for psoriasis.

The blockade of soluble TNF- $\alpha$ significantly reduces the relative gene expression and secreted protein level of pro-inflammatory cytokines

Based on the more particular understanding of the pathogenesis of psoriasis at a molecular level, the inhibition of pro-inflammatory mediators with antibodies or soluble 
receptors became the mainstream therapy to treat psoriasis. As TNF- $\alpha$ plays central role in the pathogenesis of psoriasis, it represents an active target for biologic therapies, moreover, a wide variety of TNF blocking agents have been accepted by FDA and are widely used to treat psoriasis [47].

We showed that Remicade treatment markedly reduced the relative gene expression of IL-6 after PGN stimulation (Figure 16B). This result show strong correlations with those earlier findings where the blockade of TNF- $\alpha$ by Remicade significantly reduced the relative gene expression of acute-phase proteins such as IL-1 $\beta$ and IL-6 [86]. Soluble TNF- $\alpha$ blockade also significantly down regulated CCL1 at relative gene expression (Figure 16C) and secreted protein level (Figure 16D) after prolonged PGN stimulation. To the best of our knowledge, we were the first who demonstrated the negative impact of TNF- $\alpha$ blockade on the expression of CCL1.

Taken these findings together, our data strongly suggest that in inflammatory conditions, enhanced TNF- $\alpha$ level robustly up regulates other cytokines and chemokines which have pivotal role in the maintenance of chronic inflammation. When enhanced TNF- $\alpha$ level is blocked by Remicade treatment, the expression level of the other effector mechanisms are down regulated, that is why Remicade successfully used to treat a wide variety of autoimmune inflammatory diseases [33], [154], [155]. 


\section{Summary}

In order to get a global view on the gene expression pattern of primary human iDCs after single or prolonged PGN stimulation, SAGE-Seq experiments were performed. Bioinformatics analysis of SAGE-Seq data evidenced that single or prolonged PGN stimulation resulted in significant alterations on the relative gene expression of altogether 5411 genes $(\mathrm{p}<0,05)$. In this study we mainly focused on those 566 genes which uniquely changed between $\mathrm{N}+\mathrm{PGN}$ and $\mathrm{T}+\mathrm{PGN}$ samples because they represent the differences between acute and persistent Staphylococcal infection at a relative gene expression level.

To characterize the potential relevance of these alterations pathway analysis was carried out which demonstrated massive enrichment of pathways from the function group "Immune response", "Apoptosis", "Cell cycle", "Motion" and "Energy production". Based on the results of the pathway analysis we investigated the expression patterns of individual tags. From the tags we were mostly interested in tolerizeable tags (tolerizeability means that single PGN stimulation results in a robust induction in the relative gene expression compared with naïve cells, however in T+PGN samples significant relative gene expression down regulation was detected compared with N+PGN cells) because the decreased relative gene expression level after prolonged PGN stimulation plays role in the prevention of the host against the development of serious side effects resulting from uncontrolled inflammation. Taken these findings together our experimental model together with SAGE-Seq is a valuable approach to monitor the impact of acute and persistent infection.

We also aimed to validate SAGe-Seq results on a set of genes. Based on the results of pathway analysis we have chose the members of "Immune response", "Apoptosis", and "Cell cycle" which were more accurately analyzed at relative gene expression and secreted protein level. The validation procedure was carried out on $\mathrm{mDCs}$ as well, because the presence of foreign antigens together with the inflammatory milieu induces maturation process which leads to enhanced antigen presenting capacity. In accordance with the results of SAGE-Seq experiments the QRT-PCR and ELISA-based validation procedure demonstrated that: 
- after single or prolonged PGN stimulation the host cell maintain critical balance between inflammation and tolerance to eliminate impending pathogens and to protect the host against the harmful side effects resulting from uncontrolled inflammation

- the decreased pro-inflammatory cytokine producing capacity of mDCs compared with iDCs

- PGN stimulation results in the induction of the pro-inflammatory mediators from the TNF- $\alpha$ superfamily, yet we demonstrated the tolerizeable nature of TNF- $\alpha$ and TNFAIP3, however PGN treatment significantly down regulated the relative gene expression of TNFAIP8 (which has anti-inflammatory role) compared with naïve cells

- the over expression of the tryptophan catabolizing enzymes has role in the control of acute and more interestingly in persistent Staphylococcal infection

- the enhanced relative gene expression level of SOCS1 and SOCS3 may be responsible for down regulation of pro-inflammatory effector molecules in mDCs

- at the same time the decreased level of SOCS1 and SOCS2 in iDCs after prolonged PGN stimulation strongly explains the enhanced production of inflammation-related effector molecules

- acute and persistent Staphylococcal infections decreases cell division cycle by down regulating the relative gene expression level of cyclins

- the reduced relative gene expression level of pro-apoptotic genes suggest the induction of survival mechanisms which may lead to the elimination of invading pathogens

Although the pathogenesis of psoriasis has not fully understood yet, the immunological basis of the disease has been demonstrated. It is well known that TNF- $\alpha$ has pivotal role in the pathogenesis of this disease, little is known about the other members of the TNF- $\alpha$ superfamily. To investigate their potential role we performed QRT-PCR experiments on lesional and non-lesional epidermal and dermal skin biopsy samples from psoriatic patients. To summarize these results we can conclude that beside the enhanced level of TNF- $\alpha$, the elevated expression of TNFAIP6 also has important role in the maintenance of chronic inflammation which is characteristic for psoriasis. Furthermore, the down regulation of TNFAIP3 and TNFAIP8 strongly 
suggest that braking mechanisms of inflammation are disturbed which may also explain chronic inflammation. As we detected significant induction of IL-6, IL-17A and CXCL8 in DCs after single or prolonged PGN stimulation and considering that elevated level of CCL1 is also characteristic for psoriasis we conclude that PGN stimulated DCs could be used to model the characteristics and the function of IFNprimed DCs in psoriasis.

Beside conventional treatment strategies, TNF- $\alpha$ deprivation by blocking antibodies became the most common therapeutic approach to cure psoriasis. Thus and based on our results which demonstrate that iDCs after prolonged PGN stimulation show strong correlations with psoriatic DCs we aimed to test the impact of TNF- $\alpha$ deprivation by Remicade (infliximab) which has significant impact on the relative gene expression pattern of other cytokines. It has not been published yet, that Remicade treatment significantly decreased the relative gene expression and secreted protein level of CCL1 as compared with only PGN stimulated iDCs. Our previous findings strongly suggest that ex vivo PGN stimulated DCs are identical with IFN- $\alpha$ primed psoriatic DCs. This result massively suggest that these cytokines can be used as a target gene/protein to treat plaque-type psoriasis. 


\section{Acknowledgements}

I would like to thank to Éva Kondorosi for the possibility to perform these experiments at the Institute of Biochemistry, Biological Research Centre for the Hungarian Academy of Science, previously at the Bay Zoltán Foundation for Applied Research, Institute BayGen.

I tank to István Nagy for his supervision of this work.

I am grateful to Prof. Ernő Duda and Prof. János Szabad for their patience, support and advices which helped me a lot in the past year

I thank to Zoltán Hegedüs for the excellent bioinformatics analysis of the SAGESeq experiments and for his suggestions.

I am also grateful to Prof. Dr. Lajos Kemény for providing the psoriatic skin biopsy samples.

I thank to Marianna Nagymihály and Judit Cseklye for their skilled technical assistance at SAGE-Seq experiments.

My deepest gratitude goes to my parents and Máté for their love and support through my life; this dissertation would have been impossible to accomplish without their help. 


\section{References}

1. Postel, S. and B. Kemmerling, Plant systems for recognition of pathogen-associated molecular patterns. Semin Cell Dev Biol, 2009. 20(9): p. 1025-31.

2. Tlaskalova-Hogenova, H., et al., Commensal bacteria (normal microflora), mucosal immunity and chronic inflammatory and autoimmune diseases. Immunol Lett, 2004. 93(2-3): p. 97-108.

3. Meyer-Hoffert, U., et al., Flagellin delivery by Pseudomonas aeruginosa rhamnolipids induces the antimicrobial protein psoriasin in human skin. PLoS One, 2011. 6(1): p. e16433.

4. Huang, Y.C., et al., The flexible and clustered lysine residues of human ribonuclease 7 are critical for membrane permeability and antimicrobial activity. J Biol Chem, 2007. 282(7): p. 4626-33.

5. Akira, S. and K. Takeda, Toll-like receptor signalling. Nat Rev Immunol, 2004. 4(7): p. 499511.

6. Akira, S., S. Uematsu, and O. Takeuchi, Pathogen recognition and innate immunity. Cell, 2006. 124(4): p. 783-801.

7. Goldstein, D.R., et al., Critical role of the Toll-like receptor signal adaptor protein MyD88 in acute allograft rejection. J Clin Invest, 2003. 111(10): p. 1571-8.

8. Beg, A.A., Endogenous ligands of Toll-like receptors: implications for regulating inflammatory and immune responses. Trends Immunol, 2002. 23(11): p. 509-12.

9. Kluytmans, J., A. van Belkum, and H. Verbrugh, Nasal carriage of Staphylococcus aureus: epidemiology, underlying mechanisms, and associated risks. Clin Microbiol Rev, 1997. 10(3): p. 505-20.

10. McCaig, L.F., et al., Staphylococcus aureus-associated skin and soft tissue infections in ambulatory care. Emerg Infect Dis, 2006. 12(11): p. 1715-23.

11. Lowy, F.D., Staphylococcus aureus infections. N Engl J Med, 1998. 339(8): p. 520-32.

12. Aksoy, E., M. Goldman, and F. Willems, Protein kinase C epsilon: a new target to control inflammation and immune-mediated disorders. Int J Biochem Cell Biol, 2004. 36(2): p. 183-8.

13. Karin, M., T. Lawrence, and V. Nizet, Innate immunity gone awry: linking microbial infections to chronic inflammation and cancer. Cell, 2006. 124(4): p. 823-35.

14. Kinjyo, I., et al., SOCS1/JAB is a negative regulator of LPS-induced macrophage activation. Immunity, 2002. 17(5): p. 583-91.

15. Nakagawa, R., et al., SOCS-1 participates in negative regulation of LPS responses. Immunity, 2002. 17(5): p. 677-87.

16. Boone, D.L., et al., The ubiquitin-modifying enzyme $A 20$ is required for termination of Toll-like receptor responses. Nat Immunol, 2004. 5(10): p. 1052-60.

17. West, M.A. and W. Heagy, Endotoxin tolerance: A review. Crit Care Med, 2002. 30(1 Supp): p. S64-S73.

18. Cavaillon, J.M. and M. Adib-Conquy, Bench-to-bedside review: endotoxin tolerance as a model of leukocyte reprogramming in sepsis. Crit Care, 2006. 10(5): p. 233.

19. Dobrovolskaia, M.A., et al., Induction of in vitro reprogramming by Toll-like receptor $(T L R) 2$ and TLR4 agonists in murine macrophages: effects of TLR "homotolerance" versus "heterotolerance" on NF-kappa B signaling pathway components. J Immunol, 2003. 170(1): p. 508-19.

20. Fujihara, M., et al., Molecular mechanisms of macrophage activation and deactivation by lipopolysaccharide: roles of the receptor complex. Pharmacol Ther, 2003. 100(2): p. 17194.

21. Foster, S.L., D.C. Hargreaves, and R. Medzhitov, Gene-specific control of inflammation by TLR-induced chromatin modifications. Nature, 2007. 447(7147): p. 972-8. 
22. Steinman, R.M., The dendritic cell system and its role in immunogenicity. Annu Rev Immunol, 1991. 9: p. 271-96.

23. Mellman, I. and R.M. Steinman, Dendritic cells: specialized and regulated antigen processing machines. Cell, 2001. 106(3): p. 255-8.

24. Cella, M., et al., Inflammatory stimuli induce accumulation of MHC class II complexes on dendritic cells. Nature, 1997. 388(6644): p. 782-7.

25. Akira, S., Pathogen recognition by innate immunity and its signaling. Proc Jpn Acad Ser B Phys Biol Sci, 2009. 85(4): p. 143-56.

26. Shortman, K. and S.H. Naik, Steady-state and inflammatory dendritic-cell development. Nat Rev Immunol, 2007. 7(1): p. 19-30.

27. Sallusto, F. and A. Lanzavecchia, Efficient presentation of soluble antigen by cultured human dendritic cells is maintained by granulocyte/macrophage colony-stimulating factor plus interleukin 4 and downregulated by tumor necrosis factor alpha. J Exp Med, 1994. 179(4): p. 1109-18.

28. Parlato, S., et al., Expression of CCR-7, MIP-3beta, and Th-1 chemokines in type I IFNinduced monocyte-derived dendritic cells: importance for the rapid acquisition of potent migratory and functional activities. Blood, 2001. 98(10): p. 3022-9.

29. Farkas, A., G. Tonel, and F.O. Nestle, Interferon-alpha and viral triggers promote functional maturation of human monocyte-derived dendritic cells. Br J Dermatol, 2008. 158(5): p. 921-9.

30. Farkas, A. and L. Kemeny, Interferon-alpha in the generation of monocyte-derived dendritic cells: recent advances and implications for dermatology. $\mathrm{Br} J$ Dermatol, 2011. 165(2): p. 247-54.

31. Blanco, P., et al., Induction of dendritic cell differentiation by IFN-alpha in systemic lupus erythematosus. Science, 2001. 294(5546): p. 1540-3.

32. Nestle, F.O., et al., Plasmacytoid predendritic cells initiate psoriasis through interferonalpha production. J Exp Med, 2005. 202(1): p. 135-43.

33. Lebwohl, M., Psoriasis. Lancet, 2003. 361(9364): p. 1197-204.

34. Ganguly, D., et al., Self-RNA-antimicrobial peptide complexes activate human dendritic cells through TLR7 and TLR8. J Exp Med, 2009. 206(9): p. 1983-94.

35. Lande, R., et al., Plasmacytoid dendritic cells sense self-DNA coupled with antimicrobial peptide. Nature, 2007. 449(7162): p. 564-9.

36. Farkas, A. and L. Kemeny, Monocyte-derived interferon-alpha primed dendritic cells in the pathogenesis of psoriasis: New pieces in the puzzle. Int Immunopharmacol, 2012.

37. Nestle, F.O., et al., Skin immune sentinels in health and disease. Nat Rev Immunol, 2009. 9(10): p. 679-91.

38. Lowes, M.A., A.M. Bowcock, and J.G. Krueger, Pathogenesis and therapy of psoriasis. Nature, 2007. 445(7130): p. 866-73.

39. Nagpal, S., J. Lu, and M.F. Boehm, Vitamin D analogs: mechanism of action and therapeutic applications. Curr Med Chem, 2001. 8(13): p. 1661-79.

40. Lebwohl, M., et al., Once-daily tazarotene gel versus twice-daily fluocinonide cream in the treatment of plaque psoriasis. J Am Acad Dermatol, 1998. 38(5 Pt 1): p. 705-11.

41. Stern, R.S., E.J. Liebman, and L. Vakeva, Oral psoralen and ultraviolet-A light (PUVA) treatment of psoriasis and persistent risk of nonmelanoma skin cancer. PUVA Follow-up Study. J Natl Cancer Inst, 1998. 90(17): p. 1278-84.

42. Zachariae, H., et al., Renal biopsy findings in long-term cyclosporin treatment of psoriasis. Br J Dermatol, 1997. 136(4): p. 531-5.

43. Williams, S.C., New biologic drugs get under the skin of psoriasis. Nat Med, 2012. 18(5): p. 638.

44. Leonardi, C., et al., Anti-interleukin-17 monoclonal antibody ixekizumab in chronic plaque psoriasis. N Engl J Med, 2012. 366(13): p. 1190-9. 
45. Sivamani, R.K., et al., Biologic Therapies in the Treatment of Psoriasis: A Comprehensive Evidence-Based Basic Science and Clinical Review and a Practical Guide to Tuberculosis Monitoring. Clin Rev Allergy Immunol, 2012.

46. Papp, K.A., et al., Brodalumab, an anti-interleukin-17-receptor antibody for psoriasis. N Engl J Med, 2012. 366(13): p. 1181-9.

47. Aggarwal, B.B., S.C. Gupta, and J.H. Kim, Historical perspectives on tumor necrosis factor and its superfamily: 25 years later, a golden journey. Blood, 2012. 119(3): p. 651-65.

48. Schena, M., et al., Quantitative monitoring of gene expression patterns with a complementary DNA microarray. Science, 1995. 270(5235): p. 467-70.

49. Matsumura, H., et al., High-throughput SuperSAGE for digital gene expression analysis of multiple samples using next generation sequencing. PLoS One, 2010. 5(8): p. e12010.

50. Velculescu, V.E., B. Vogelstein, and K.W. Kinzler, Analysing uncharted transcriptomes with SAGE. Trends Genet, 2000. 16(10): p. 423-5.

51. Nagy, I., et al., In vitro interactions of Candida parapsilosis wild type and lipase deficient mutants with human monocyte derived dendritic cells. BMC Microbiol, 2011. 11: p. 122.

52. Belso, N., et al., Differential expression of D-type cyclins in HaCaT keratinocytes and in psoriasis. J Invest Dermatol, 2008. 128(3): p. 634-42.

53. Lash, A.E., et al., SAGEmap: a public gene expression resource. Genome Res, 2000. 10(7): p. 1051-60.

54. Ogata, H., et al., KEGG: Kyoto Encyclopedia of Genes and Genomes. Nucleic Acids Res, 1999. 27(1): p. 29-34.

55. Castiello, L., et al., Monocyte-derived DC maturation strategies and related pathways: a transcriptional view. Cancer Immunol Immunother, 2011. 60(4): p. 457-66.

56. Meylan, F., A.C. Richard, and R.M. Siegel, TL1A and DR3, a TNF family ligand-receptor pair that promotes lymphocyte costimulation, mucosal hyperplasia, and autoimmune inflammation. Immunol Rev, 2011. 244(1): p. 188-96.

57. Bamias, G., et al., Upregulation and nuclear localization of TNF-like cytokine 1A (TL1A) and its receptors DR3 and DcR3 in psoriatic skin lesions. Exp Dermatol, 2011. 20(9): p. 725-31.

58. Milner, C.M. and A.J. Day, TSG-6: a multifunctional protein associated with inflammation. J Cell Sci, 2003. 116(Pt 10): p. 1863-73.

59. Tammi, M.I., A.J. Day, and E.A. Turley, Hyaluronan and homeostasis: a balancing act. J Biol Chem, 2002. 277(7): p. 4581-4.

60. Van Parijs, L. and A.K. Abbas, Homeostasis and self-tolerance in the immune system: turning lymphocytes off. Science, 1998. 280(5361): p. 243-8.

61. Wahl, S.M., J. Wen, and N. Moutsopoulos, TGF-beta: a mobile purveyor of immune privilege. Immunol Rev, 2006. 213: p. 213-27.

62. Nagata, S. and T. Suda, Fas and Fas ligand: Ipr and gld mutations. Immunol Today, 1995. 16(1): p. 39-43.

63. Lee, E.G., et al., Failure to regulate TNF-induced NF-kappaB and cell death responses in A20-deficient mice. Science, 2000. 289(5488): p. 2350-4.

64. Hammer, G.E., et al., Expression of A20 by dendritic cells preserves immune homeostasis and prevents colitis and spondyloarthritis. Nat Immunol, 2011. 12(12): p. 1184-93.

65. Kool, M., et al., The ubiquitin-editing protein A20 prevents dendritic cell activation, recognition of apoptotic cells, and systemic autoimmunity. Immunity, 2011. 35(1): p. 8296.

66. Tavares, R.M., et al., The ubiquitin modifying enzyme $A 20$ restricts $B$ cell survival and prevents autoimmunity. Immunity, 2010. 33(2): p. 181-91.

67. Sun, H., et al., TIPE2, a negative regulator of innate and adaptive immunity that maintains immune homeostasis. Cell, 2008. 133(3): p. 415-26. 
68. Zhang, G., et al., Tissue-specific expression of TIPE2 provides insights into its function. Mol Immunol, 2010. 47(15): p. 2435-42.

69. Zhang, L., et al., The unique expression profile of human TIPE2 suggests new functions beyond its role in immune regulation. Mol Immunol, 2011. 48(9-10): p. 1209-15.

70. Gadina, M., et al., Signaling by type I and II cytokine receptors: ten years after. Curr Opin Immunol, 2001. 13(3): p. 363-73.

71. Dalpke, A., et al., Regulation of innate immunity by suppressor of cytokine signaling (SOCS) proteins. Immunobiology, 2008. 213(3-4): p. 225-35.

72. Hanada, T., et al., Suppressor of cytokine signaling-1 is essential for suppressing dendritic cell activation and systemic autoimmunity. Immunity, 2003. 19(3): p. 437-50.

73. Posselt, G., et al., Suppressor of cytokine signaling 2 is a feedback inhibitor of TLRinduced activation in human monocyte-derived dendritic cells. J Immunol, 2011. 187(6): p. 2875-84.

74. Babon, J.J., et al., Suppression of cytokine signaling by SOCS3: characterization of the mode of inhibition and the basis of its specificity. Immunity, 2012. 36(2): p. 239-50.

75. Daubener, W. and C.R. MacKenzie, IFN-gamma activated indoleamine 2,3-dioxygenase activity in human cells is an antiparasitic and an antibacterial effector mechanism. Adv Exp Med Biol, 1999. 467: p. 517-24.

76. Ravishankar, B., et al., Tolerance to apoptotic cells is regulated by indoleamine 2,3dioxygenase. Proc Natl Acad Sci U S A, 2012. 109(10): p. 3909-14.

77. Munn, D.H., et al., GCN2 kinase in T cells mediates proliferative arrest and anergy induction in response to indoleamine 2,3-dioxygenase. Immunity, 2005. 22(5): p. 633-42.

78. Baban, B., et al., A minor population of splenic dendritic cells expressing CD19 mediates IDO-dependent T cell suppression via type I IFN signaling following B7 ligation. Int Immunol, 2005. 17(7): p. 909-19.

79. Ito, M., et al., Gene expression of enzymes for tryptophan degradation pathway is upregulated in the skin lesions of patients with atopic dermatitis or psoriasis. J Dermatol Sci, 2004. 36(3): p. 157-64.

80. Nigg, E.A., Cyclin-dependent protein kinases: key regulators of the eukaryotic cell cycle. Bioessays, 1995. 17(6): p. 471-80.

81. Hueber, A.J. and I.B. McInnes, Immune regulation in psoriasis and psoriatic arthritis-recent developments. Immunol Lett, 2007. 114(2): p. 59-65.

82. Nickoloff, B.J., et al., The cytokine and chemokine network in psoriasis. Clin Dermatol, 2007. 25(6): p. 568-73.

83. Schottelius, A.J., et al., Biology of tumor necrosis factor-alpha-implications for psoriasis. Exp Dermatol, 2004. 13(4): p. 193-222.

84. Farkas, A. and L. Kemeny, Monocyte-derived interferon-alpha primed dendritic cells in the pathogenesis of psoriasis: new pieces in the puzzle. Int Immunopharmacol, 2012. 13(2): p. 215-8.

85. Gros, E., et al., Expression of chemokines and chemokine receptors in lesional and nonlesional upper skin of patients with atopic dermatitis. J Allergy Clin Immunol, 2009. 124(4): p. 753-60 e1.

86. Musacchio, E., et al., The tumor necrosis factor-\{alpha\}-blocking agent infliximab inhibits interleukin 1 beta (IL-1beta) and IL-6 gene expression in human osteoblastic cells. J Rheumatol, 2009. 36(8): p. 1575-9.

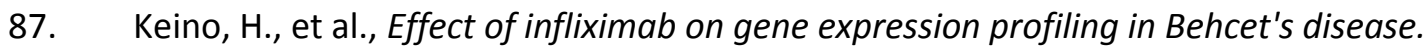
Invest Ophthalmol Vis Sci, 2011. 52(10): p. 7681-6.

88. Banchereau, J. and R.M. Steinman, Dendritic cells and the control of immunity. Nature, 1998. 392 (6673): p. 245-52.

89. Zlotnik, A. and O. Yoshie, Chemokines: a new classification system and their role in immunity. Immunity, 2000. 12(2): p. 121-7. 
90. Muller, A., et al., Involvement of chemokine receptors in breast cancer metastasis. Nature, 2001. 410(6824): p. 50-6.

91. Yao, Z., et al., Human IL-17: a novel cytokine derived from T cells. J Immunol, 1995. 155(12): p. 5483-6.

92. Fossiez, F., et al., $T$ cell interleukin-17 induces stromal cells to produce proinflammatory and hematopoietic cytokines. J Exp Med, 1996. 183(6): p. 2593-603.

93. Ye, P., et al., Requirement of interleukin 17 receptor signaling for lung CXC chemokine and granulocyte colony-stimulating factor expression, neutrophil recruitment, and host defense. J Exp Med, 2001. 194(4): p. 519-27.

94. Happel, K.I., et al., Divergent roles of IL-23 and IL-12 in host defense against Klebsiella pneumoniae. J Exp Med, 2005. 202(6): p. 761-9.

95. Ferretti, S., et al., IL-17, produced by lymphocytes and neutrophils, is necessary for lipopolysaccharide-induced airway neutrophilia: IL-15 as a possible trigger. J Immunol, 2003. 170(4): p. 2106-12.

96. Kotake, S., et al., IL-17 in synovial fluids from patients with rheumatoid arthritis is a potent stimulator of osteoclastogenesis. J Clin Invest, 1999. 103(9): p. 1345-52.

97. Fujino, S., et al., Increased expression of interleukin 17 in inflammatory bowel disease. Gut, 2003. 52(1): p. 65-70.

98. Albanesi, C., A. Cavani, and G. Girolomoni, IL-17 is produced by nickel-specific $T$ lymphocytes and regulates ICAM-1 expression and chemokine production in human keratinocytes: synergistic or antagonist effects with IFN-gamma and TNF-alpha. J Immunol, 1999. 162(1): p. 494-502.

99. Lyakh, L., et al., Regulation of interleukin-12/interleukin-23 production and the T-helper 17 response in humans. Immunol Rev, 2008. 226: p. 112-31.

100. Oppmann, B., et al., Novel p19 protein engages IL-12p40 to form a cytokine, IL-23, with biological activities similar as well as distinct from IL-12. Immunity, 2000. 13(5): p. 71525.

101. Aggarwal, S., et al., Interleukin-23 promotes a distinct CD4 T cell activation state characterized by the production of interleukin-17. J Biol Chem, 2003. 278(3): p. 1910-4.

102. Wilson, N.J., et al., Development, cytokine profile and function of human interleukin 17producing helper T cells. Nat Immunol, 2007. 8(9): p. 950-7.

103. Kurzeja, M., L. Rudnicka, and M. Olszewska, New interleukin-23 pathway inhibitors in dermatology: ustekinumab, briakinumab, and secukinumab. Am J Clin Dermatol, 2011. 12(2): p. 113-25.

104. Lee, E., et al., Increased expression of interleukin $23 p 19$ and p40 in lesional skin of patients with psoriasis vulgaris. J Exp Med, 2004. 199(1): p. 125-30.

105. Wong, C.K., et al., Hyperproduction of IL-23 and IL-17 in patients with systemic lupus erythematosus: implications for Th17-mediated inflammation in auto-immunity. Clin Immunol, 2008. 127(3): p. 385-93.

106. Shah, K., et al., Dysregulated balance of Th17 and Th1 cells in systemic lupus erythematosus. Arthritis Res Ther, 2010. 12(2): p. R53.

107. Kim, H.R., et al., The clinical role of IL-23p19 in patients with rheumatoid arthritis. Scand J Rheumatol, 2007. 36(4): p. 259-64.

108. Schmidt, C., et al., Expression of interleukin-12-related cytokine transcripts in inflammatory bowel disease: elevated interleukin-23p19 and interleukin-27p28 in Crohn's disease but not in ulcerative colitis. Inflamm Bowel Dis, 2005. 11(1): p. 16-23.

109. Pivarcsi, A., et al., CC chemokine ligand 18, an atopic dermatitis-associated and dendritic cell-derived chemokine, is regulated by staphylococcal products and allergen exposure. J Immunol, 2004. 173(9): p. 5810-7.

110. Kawai, T. and S. Akira, The role of pattern-recognition receptors in innate immunity: update on Toll-like receptors. Nat Immunol, 2010. 11(5): p. 373-84. 
111. Morgan, M.J. and Z.G. Liu, Reactive oxygen species in TNFalpha-induced signaling and cell death. Mol Cells, 2010. 30(1): p. 1-12.

112. Aggarwal, B.B., et al., Inflammation and cancer: how hot is the link? Biochem Pharmacol, 2006. 72(11): p. 1605-21.

113. Brietzke, E. and F. Kapczinski, TNF-alpha as a molecular target in bipolar disorder. Prog Neuropsychopharmacol Biol Psychiatry, 2008. 32(6): p. 1355-61.

114. Vinay, D.S. and B.S. Kwon, The tumour necrosis factor/TNF receptor superfamily: therapeutic targets in autoimmune diseases. Clin Exp Immunol, 2011. 164(2): p. 145-57.

115. Bodmer, J.L., P. Schneider, and J. Tschopp, The molecular architecture of the TNF superfamily. Trends Biochem Sci, 2002. 27(1): p. 19-26.

116. Migone, T.S., et al., TL1A is a TNF-like ligand for DR3 and TR6/DcR3 and functions as a T cell costimulator. Immunity, 2002. 16(3): p. 479-92.

117. Bamias, G., et al., Expression, localization, and functional activity of TL1A, a novel Th1polarizing cytokine in inflammatory bowel disease. J Immunol, 2003. 171(9): p. 4868-74.

118. Bamias, G., et al., Role of TL1A and its receptor DR3 in two models of chronic murine ileitis. Proc Natl Acad Sci U S A, 2006. 103(22): p. 8441-6.

119. Byrne, G.I., L.K. Lehmann, and G.J. Landry, Induction of tryptophan catabolism is the mechanism for gamma-interferon-mediated inhibition of intracellular Chlamydia psittaci replication in T24 cells. Infect Immun, 1986. 53(2): p. 347-51.

120. Carlin, J.M., E.C. Borden, and G.I. Byrne, Interferon-induced indoleamine 2,3-dioxygenase activity inhibits Chlamydia psittaci replication in human macrophages. J Interferon Res, 1989. 9(3): p. 329-37.

121. Widner, B., G. Weiss, and D. Fuchs, Tryptophan degradation to control T-cell responsiveness. Immunol Today, 2000. 21(5): p. 250.

122. Mellor, A.L. and D.H. Munn, Tryptophan catabolism and T-cell tolerance: immunosuppression by starvation? Immunol Today, 1999. 20(10): p. 469-73.

123. Byrne, G.I., et al., Induction of tryptophan degradation in vitro and in vivo: a gammainterferon-stimulated activity. J Interferon Res, 1986. 6(4): p. 389-96.

124. Werner, E.R., et al., Human macrophages degrade tryptophan upon induction by interferon-gamma. Life Sci, 1987. 41(3): p. 273-80.

125. Zhou, L., et al., Indoleamine 2,3-dioxygenase expression in human inflammatory bowel disease. Eur J Gastroenterol Hepatol, 2012. 24(6): p. 695-701.

126. Pestka, S., et al., Interleukin-10 and related cytokines and receptors. Annu Rev Immunol, 2004. 22: p. 929-79.

127. Gerlini, G., et al., Metastatic melanoma secreted IL-10 down-regulates CD1 molecules on dendritic cells in metastatic tumor lesions. Am J Pathol, 2004. 165(6): p. 1853-63.

128. Maina, V., et al., Coregulation in human leukocytes of the long pentraxin PTX3 and TSG6. J Leukoc Biol, 2009. 86(1): p. 123-32.

129. Oshima, N., et al., A2O is an early responding negative regulator of Toll-like receptor 5 signalling in intestinal epithelial cells during inflammation. Clin Exp Immunol, 2010. 159(2): p. 185-98.

130. Woodward, M.J., et al., Tnfaip8 is an essential gene for the regulation of glucocorticoidmediated apoptosis of thymocytes. Cell Death Differ, 2010. 17(2): p. 316-23.

131. Yoshimura, A., T. Naka, and M. Kubo, SOCS proteins, cytokine signalling and immune regulation. Nat Rev Immunol, 2007. 7(6): p. 454-65.

132. Madonna, S., et al., Anti-apoptotic effects of suppressor of cytokine signaling 3 and 1 in psoriasis. Cell Death Dis, 2012. 3: p. e334.

133. Chen, M. and J. Wang, Programmed cell death of dendritic cells in immune regulation. Immunol Rev, 2010. 236: p. 11-27.

134. Wilson, N.S., V. Dixit, and A. Ashkenazi, Death receptor signal transducers: nodes of coordination in immune signaling networks. Nat Immunol, 2009. 10(4): p. 348-55. 
135. Tourneur, L. and G. Chiocchia, FADD: a regulator of life and death. Trends Immunol, 2010. 31(7): p. 260-9.

136. Bonnet, M.C., et al., The adaptor protein FADD protects epidermal keratinocytes from necroptosis in vivo and prevents skin inflammation. Immunity, 2011. 35(4): p. 572-82.

137. Fitch, E., et al., Pathophysiology of psoriasis: recent advances on IL-23 and Th17 cytokines. Curr Rheumatol Rep, 2007. 9(6): p. 461-7.

138. Simonart, T. and M. Heenen, $T$ cell/keratinocyte interactions in psoriasis: where is the trigger? Br J Dermatol, 2007. 156(1): p. 171-2.

139. Nestle, F.O., L.A. Turka, and B.J. Nickoloff, Characterization of dermal dendritic cells in psoriasis. Autostimulation of T lymphocytes and induction of Th1 type cytokines. J Clin Invest, 1994. 94(1): p. 202-9.

140. Zaba, L.C., et al., Psoriasis is characterized by accumulation of immunostimulatory and Th1/Th17 cell-polarizing myeloid dendritic cells. J Invest Dermatol, 2009. 129(1): p. 7988.

141. Lee, T.H., H.G. Wisniewski, and J. Vilcek, A novel secretory tumor necrosis factorinducible protein (TSG-6) is a member of the family of hyaluronate binding proteins, closely related to the adhesion receptor CD44. J Cell Biol, 1992. 116(2): p. 545-57.

142. Lee, T.H., et al., Transcriptional regulation of TSG6, a tumor necrosis factor-and interleukin-1-inducible primary response gene coding for a secreted hyaluronan-binding protein. J Biol Chem, 1993. 268(9): p. 6154-60.

143. Wisniewski, H.G. and J. Vilcek, TSG-6: an IL-1/TNF-inducible protein with antiinflammatory activity. Cytokine Growth Factor Rev, 1997. 8(2): p. 143-56.

144. Mindrescu, C., et al., Amelioration of collagen-induced arthritis in DBA/1J mice by recombinant TSG-6, a tumor necrosis factor/interleukin-1-inducible protein. Arthritis Rheum, 2000. 43(12): p. 2668-77.

145. Mindrescu, C., et al., Reduced susceptibility to collagen-induced arthritis in DBA/1J mice expressing the TSG-6 transgene. Arthritis Rheum, 2002. 46(9): p. 2453-64.

146. Bardos, T., et al., Anti-inflammatory and chondroprotective effect of TSG-6 (tumor necrosis factor-alpha-stimulated gene-6) in murine models of experimental arthritis. Am J Pathol, 2001. 159(5): p. 1711-21.

147. Lee, R.H., et al., Intravenous hMSCs improve myocardial infarction in mice because cells embolized in lung are activated to secrete the anti-inflammatory protein TSG-6. Cell Stem Cell, 2009. 5(1): p. 54-63.

148. Roddy, G.W., et al., Action at a distance: systemically administered adult stem/progenitor cells (MSCs) reduce inflammatory damage to the cornea without engraftment and primarily by secretion of TNF-alpha stimulated gene/protein 6. Stem Cells, 2011. 29(10): p. 1572-9.

149. Oh, J.Y., et al., Anti-inflammatory protein TSG-6 reduces inflammatory damage to the cornea following chemical and mechanical injury. Proc Natl Acad Sci U S A, 2010. 107(39): p. 16875-80.

150. Opipari, A.W., Jr., M.S. Boguski, and V.M. Dixit, The A20 cDNA induced by tumor necrosis factor alpha encodes a novel type of zinc finger protein. J Biol Chem, 1990. 265(25): p. 14705-8.

151. Werner, S.L., et al., Encoding NF-kappaB temporal control in response to TNF: distinct roles for the negative regulators IkappaBalpha and A20. Genes Dev, 2008. 22(15): p. 2093-101.

152. Nair, R.P., et al., Genome-wide scan reveals association of psoriasis with IL-23 and NFkappaB pathways. Nat Genet, 2009. 41(2): p. 199-204.

153. Strange, A., et al., A genome-wide association study identifies new psoriasis susceptibility loci and an interaction between HLA-C and ERAP1. Nat Genet, 2010. 42(11): p. 985-90. 
154. Ogilvie, A.L., et al., Treatment of psoriatic arthritis with antitumour necrosis factor-alpha antibody clears skin lesions of psoriasis resistant to treatment with methotrexate. $\mathrm{Br} \mathrm{J}$ Dermatol, 2001. 144(3): p. 587-9.

155. Chey, W.Y., et al., Infliximab for refractory ulcerative colitis. Am J Gastroenterol, 2001. 96(8): p. 2373-81. 